\title{
Article
}

\section{Lytic Polysaccharide Monooxygenase from Talaromyces amestolkiae with an Enigmatic Linker-like Region: The Role of This Enzyme on Cellulose Saccharification}

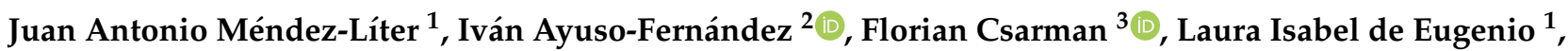 \\ Noa Míguez ${ }^{4}$, Francisco J. Plou ${ }^{4}\left(\mathbb{D}\right.$, Alicia Prieto ${ }^{1}\left(\mathbb{D}\right.$, Roland Ludwig ${ }^{3}\left(\mathbb{C}\right.$ and María Jesús Martínez ${ }^{1, *(\mathbb{D}}$
}

check for updates

Citation: Méndez-Líter, J.A.

Ayuso-Fernández, I.; Csarman, F.; de Eugenio, L.I.; Míguez, N.; Plou, F.J.;

Prieto, A.; Ludwig, R.; Martínez, M.J. Lytic Polysaccharide Monooxygenase from Talaromyces amestolkiae with an Enigmatic Linker-like Region: The Role of This Enzyme on Cellulose Saccharification. Int. J. Mol. Sci. 2021, 22, 13611. https://doi.org/10.3390/ ijms222413611

Academic Editors: Marco Moracci, Beatrice Cobucci-Ponzano, Samir Bejar and Andrea Strazzulli

Received: 22 November 2021 Accepted: 16 December 2021 Published: 19 December 2021

Publisher's Note: MDPI stays neutral with regard to jurisdictional claims in published maps and institutional affiliations.

Copyright: (C) 2021 by the authors. Licensee MDPI, Basel, Switzerland. This article is an open access article distributed under the terms and conditions of the Creative Commons Attribution (CC BY) license (https:// creativecommons.org/licenses/by/ $4.0 /)$.
1 Department of Microbial and Plant Biotechnology, Centro de Investigaciones Biológicas Margarita Salas, Spanish National Research Council (CSIC), Ramiro de Maeztu 9, 28040 Madrid, Spain; jmendez@cib.csic.es (J.A.M.-L.); lidem@cib.csic.es (L.I.d.E.); aliprieto@cib.csic.es (A.P.)

2 Faculty of Chemistry, Biotechnology and Food Science, Norwegian University of Life Sciences (NMBU), 1462 Ås, Norway; ivan.ayuso-fernandez@nmbu.no

3 Department of Food Science and Technology, BOKU-University of Natural Resources and Life Sciences, Muthgasse 11, 1190 Vienna, Austria; florian.csarman@boku.ac.at (F.C.); roland.ludwig@boku.ac.at (R.L.)

4 Instituto de Catálisis y Petroleoquímica, Spanish National Research Council (CSIC), Marie Curie 2, 28049 Madrid, Spain; noa.miguez@cisc.es (N.M.); fplou@icp.csic.es (F.J.P.)

* Correspondence: mjmartinez@cib.csic.es

Abstract: The first lytic polysaccharide monooxygenase (LPMO) detected in the genome of the widespread ascomycete Talaromyces amestolkiae (TamAA9A) has been successfully expressed in Pichia pastoris and characterized. Molecular modeling of TamAA9A showed a structure similar to those from other AA9 LPMOs. Although fungal LPMOs belonging to the genera Penicillium or Talaromyces have not been analyzed in terms of regioselectivity, phylogenetic analyses suggested $\mathrm{C} 1 / \mathrm{C} 4$ oxidation which was confirmed by HPAEC. To ascertain the function of a C-terminal linker-like region present in the wild-type sequence of the LPMO, two variants of the wild-type enzyme, one without this sequence and one with an additional C-terminal carbohydrate binding domain (CBM), were designed. The three enzymes (native, without linker and chimeric variant with a CBM) were purified in two chromatographic steps and were thermostable and active in the presence of $\mathrm{H}_{2} \mathrm{O}_{2}$. The transition midpoint temperature of the wild-type LPMO $\left(\mathrm{Tm}=67.7^{\circ} \mathrm{C}\right)$ and its variant with only the catalytic domain $\left(\mathrm{Tm}=67.6^{\circ} \mathrm{C}\right)$ showed the highest thermostability, whereas the presence of a CBM reduced it $\left(\mathrm{Tm}=57.8^{\circ} \mathrm{C}\right)$ and indicates an adverse effect on the enzyme structure. Besides, the potential of the different T. amestolkiae LPMO variants for their application in the saccharification of cellulosic and lignocellulosic materials was corroborated.

Keywords: LPMO; wheat straw; brewers spent grain; saccharification; AA9; oxidative biomass degradation

\section{Introduction}

One of the most important applications for plant biomass valorization is related to the production of second-generation ethanol, based on the degradation of lignocellulosic biomass, where the sources of fermentable sugars are cellulose and hemicellulose [1]. After deconstruction of the plant cell wall and removal of lignin [2], plant polysaccharides must be hydrolyzed into their corresponding monosaccharides by the concerted action of different types of enzymes, mostly glycosyl hydrolases (GHs). These enzymes catalyze the hydrolysis of the glycosidic bond between two monosaccharides, or between a carbohydrate and an aglycone [3].

Cellulose exploitation is particularly interesting, since it is the most abundant polysaccharide on the planet and the glucose derived from it can be used in a large number of applications. In general, it can be stated that all the enzymes that degrade cellulose exhibit 
a synergistic behavior, due to the fact that they work in a coordinated way $[4,5]$. However, cellulose has crystalline areas that are difficult for glycosyl hydrolases to access, and the model for the whole degradation of this polysaccharide seemed incomplete. The pioneer studies developed by Reese on cellulose degradation [6] suggested the possibility of the coexistence of a two-component system: (1) an unidentified component which would act in the first place reducing the crystallinity of the cellulose, and (2) the glycosyl hydrolases, that would degrade the polymer into glucose [7]. Several decades later, the first step was found to be due to the action of fungal and bacterial copper-containing lytic polysaccharide monooxygenases (LPMOs) [8]. These novel catalysts were included in the CAZy database [9], in the class of auxiliary activities, and currently belong to families AA9, $10,11,13,14,1516$, and 17 . Enzymes from the AA9 family are N-terminal methylated enzymes, usually glycosylated, that act on $\beta-1,4$ linked glucoses and are found exclusively in fungi. The number of potential LPMO genes discovered in fungal genomes has increased exponentially in recent years, demonstrating that they are ancient enzymes and offer a vast new field to study cellulose degradation. However, despite the broad diversity of LPMOs, the number of enzymes isolated and characterized biochemically and catalytically up to date is still quite low.

LPMOs are monocopper enzymes in which copper is coordinated by a conserved histidine brace [10]. Their catalytic mechanism starts with the reduction of the solventexposed $\mathrm{Cu}^{2+}$ to generate reactive $\mathrm{Cu}^{1+}$ species by an external source of electrons. $\mathrm{Cu}^{1+}$ further reacts with the substrate using an $\mathrm{O}$-containing co-substrate. It was generally assumed that LPMOs used $\mathrm{O}_{2}$ in a monooxygenase reaction, but the true nature of the co-substrate has been questioned recently since $\mathrm{H}_{2} \mathrm{O}_{2}$ outperforms $\mathrm{O}_{2}$ [11,12]. Either way, cellulose-active LPMOs will hydroxylate the $\mathrm{C} 1$ or $\mathrm{C} 4$ carbons that participate in the glycosidic bond between two glucose residues in the polymer. Cellulose-acting LPMOs extract a hydrogen atom from $\mathrm{C} 1$ or $\mathrm{C} 4$ at the cleavable glycosidic bond, followed by hydroxylation of the resulting radical substrate. Besides, some LPMOs oxidize both C1 and C4, which means they have a mixed product profile that includes double oxidation products [13]. This is an important feature since LPMOs are usually classified based on their regioselectivity. $\mathrm{C} 1$ oxidation generates an oxidized glucose which is a lactone with a nonreducing end. It is important to note, that, depending on the $\mathrm{pH}$, this lactone is in equilibrium with the aldonic acid form, which predominates at a neutral $\mathrm{pH}$. On the other hand, $\mathrm{C} 4$ oxidation leads to the formation of a reducing end, a 4-ketosaccharide which, in aqueous conditions, is converted into a gem diol. Double oxidized products in C1-C4 have both degradation products simultaneously (Figure 1).

As mentioned before, LPMOs need an external source of electrons to reduce the copper at the active site. Although in vitro experiments generally use ascorbic acid as the reductant molecule [7], in nature, a variety of phenolic compounds produced from lignocellulose degradation could serve as electron donors to LPMOs [14]. Besides, it was also postulated that LPMOs could act in coordination with cellobiose dehydrogenase as a natural electron donor [15]. Moreover, the synergistic action with other enzymes, such as formaldehyde oxidoreductase or the glucose-methanol-choline oxidoreductases [16], was also identified as a potential source of electron donors for LPMOs. Regarding the binding to cellulose, approximately $30 \%$ of LPMOs contain carbohydrate binding modules (CBMs) [17], which belong mainly to the CBM1 family in the case of fungal LPMOs [18]. In general, it is considered that CBMs play a crucial role to tether the catalytic domain containing the active site in close proximity with its substrate. This role could be even more important than in GHs, since LPMOs avoid oxidative self-inactivation. The biotechnological applications of LPMOs are a field in full expansion. In general, it is well proven that these biocatalysts are an important piece for cellulose deconstruction [19]: the addition of LPMOs to cellulolytic cocktails has improved cellulose hydrolysis, which has changed the vision on how to degrade this polysaccharide [8]. Until today, one of the main bottlenecks when working with LPMOs has been its functional characterization and the measurement of its physicochemical properties [20]. To overcome the limitations and difficulties for the detection of 
oxidized oligosaccharides [20,21], a few colorimetric assays have been developed [22,23] to easily follow LPMO activity. That is the case for the oxidation of 2,6-dimethoxyphenol (2,6-DMP) to the colored product coerulignone, using $\mathrm{H}_{2} \mathrm{O}_{2}$ as co-substrate [22].

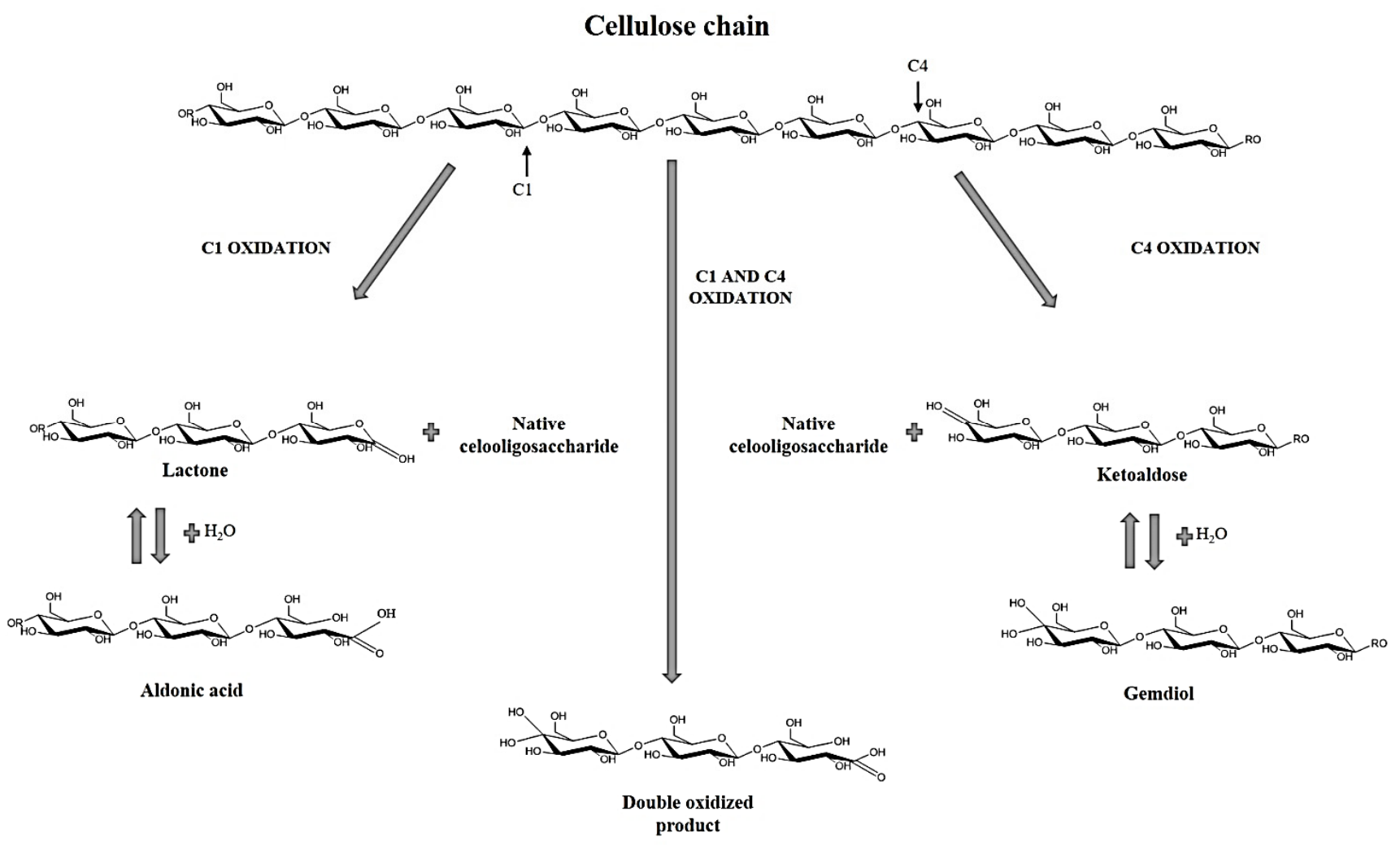

Figure 1. Reaction scheme of LPMO cellulose degradation, showing the products depending of the regioselectivity of the enzymes.

In the above overall context, the ascomycete T. amestolkiae is being studied for its ability to secrete powerful cellulolytic enzyme cocktails when growing on different carbon sources [24], and many of the enzymes involved have been purified and characterized [25]. The analysis of its genome revealed that the number of genes encoding for putative enzymes implicated in plant cell wall degradation was much higher than for T. reesei and other cellulolytic model fungi [24]. It should be noted that the discovery and characterization of LPMOs from Penicillium or Talaromyces (its perfect form) species is currently very scarce, which is intriguing considering their excellent performance in the degradation of lignocellulosic biomass $[26,27]$. In this work, a gene that encodes for a putative LPMO in the genome of T. amestolkiae, as well as two variants of this enzyme, have been successfully expressed in P. pastoris and the recombinant proteins purified and characterized. In addition, another two variants of the LPMO were designed to compare properties. The role of these LPMOs for enhanced cellulose hydrolysis, as well as for the saccharification of lignocellulosic residues, have been studied.

\section{Results and Discussion}

\subsection{Cloning, Production, and Purification of TamAA9A}

In recent years, several studies have demonstrated that, in the presence of inducers of lignocellulolytic activities, the ascomycete T. amestolkiae produces a set of highly efficient glycosyl hydrolases (GHs), especially $\beta$-glucosidases and $\beta$-xylosidases [24,28-32]. These enzymatic cocktails rich in GHs were successfully applied to saccharify wheat straw [24] and the outstanding activity of the $\beta$-glucosidases secreted by this organism has been 
corroborated $[28,29]$. However, the potential of other interesting enzymes of this organism related to lignocellulose degradation, i.e., LPMO, remains unknown.

In a previous work, a single gene coding for a putative LPMO (TamAA9A protein) was detected in the annotated genome of T. amestolkiae (GenBank accession no. MIKG00000000) [24]. To confirm its expression, RNA from 7-day-old cultures of T. amestolkiae growing in Mandels medium, induced with crystalline cellulose as a carbon source, was extracted and subsequently retrotranscribed to obtain cDNA. The gene consisted of a sequence of $1060 \mathrm{bp}$, including one intron, and encoded a 333 amino acid protein (Figure S1). The peptide sequence of TamAA9A shows a high similarity to those of other AA9 fungal LPMOs, except for the C-terminal region. When modeled (Figure S2), this part of the protein was modeled as a random coil. This disordered structure is frequently found in cellulases, acting as a linker between the catalytic domain and a CBM [33]. The function of this "linker-like" domain in the LPMO of T. amestolkiae is quite uncertain, especially considering that the gene lacks a CBM sequence after the LPMO coding region. A very similar case was reported by Kojima et al. [34], when working with an AA9 LPMO from Gloeophyllum trabeum, in which alternative splice processing generated two variants of the enzyme, one of them with a C-terminal domain comprising approximately 55 residues without a predicted function. Although the exact role of this domain remains uncertain, a linker region that connects the catalytic domain and a CBM1 has been described in an LPMO produced by Hypocrea jecorina (HjLPMO9A) [35]. X-ray analysis of a truncated form of this enzyme demonstrated that the linker is an integral part of the structure of the catalytic domain of this LPMO, covering a hydrophobic patch [35].

To identify the role of the "linker-like" region in this LPMO, three different enzyme variants were constructed and expressed in P. pastoris: (i) the complete wild-type enzyme (TamAA9A-WT), including the catalytic domain and the "linker-like" region; (ii) only the catalytic domain (TamAA9A-CD) without the "linker-like" region; and (iii) a chimeric variant of the whole LPMO that incorporates the functional CBM of family 1 , from a $\beta$-glucosidase of the same fungus [28] attached to the linker (TamAA9A-CBM).

Initially, the sequence of TamAA9-WT fused to the $\alpha$-factor signal sequence, which usually enhances protein secretion, was expressed in P. pastoris. The transformants were isolated and grown in YEPS liquid medium for 5 days, monitoring the protein amount. However, no recombinant protein was detected by SDS-PAGE, which could be due to the ambiguous processing of the $\mathrm{N}$-terminal sequence in P. pastoris when expressing a very high amount of enzyme [36]. At high expression levels, the proteins produced in this host are prone to have some additional amino acids in this region, due to protease miscleavage. Since N-terminal integrity has been proved to be very relevant for LPMO expression [20,37], the introduction of additional amino acids in this zone could produce inactive proteins. Then, the three LPMO variants with their native signal peptide of TamAA9A were cloned into the pPICZ vector, following the successful strategy performed by Kittl et al. for Neurospora crassa LPMO expression [23]. Samples taken from these cultures did not allow us to detect enzyme activity on 2,6-DMP oxidation, probably because enzyme activity could be inhibited by some medium components of the complex YEPS medium, as postulated for other fungal LPMOs [38]. However, the bands corresponding to the three recombinant versions of the LPMO were observed by SDS-PAGE analysis, confirming their secretion into the culture medium (Figure S3).

After this initial screening, the clones yielding the highest protein concentration were chosen for enzyme production in a 5-L bioreactor, monitoring the cultures for wet biomass and LPMO activity with 2,6-DMP as the substrate, and analyzing the supernatants by SDSPAGE at the final incubation time (Figure 2A). After 4 days of fermentation a wet biomass of 209, 240, and $280 \mathrm{~g} / \mathrm{L}$ for TamAA9A-WT, TamAA9A-CD and TamAA9A-CBM, respectively was determined. The bioreactor cultivations were carried out using a minimal medium, and the lack of interfering components allowed the successful monitoring of enzyme production by following the activity of the supernatants against 2,6-DMP $(138,171$ and $240 \mathrm{U} / \mathrm{L}$ for TamAA9A-WT, TamAA9A-CD and TamAA9A-CBM, respectively). The three LPMO 
variants were purified to homogeneity after two chromatographic steps (hydrophobic interaction and anion exchange chromatography, Figure 2B,C), as corroborated by SDSPAGE (Figure 2D).

A

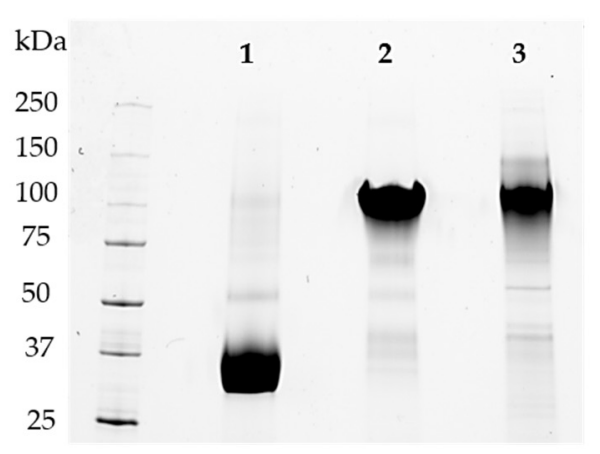

C

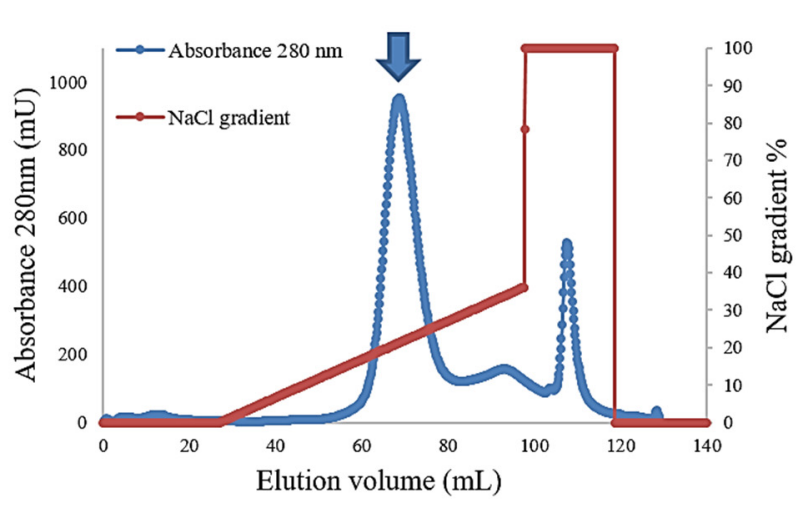

B

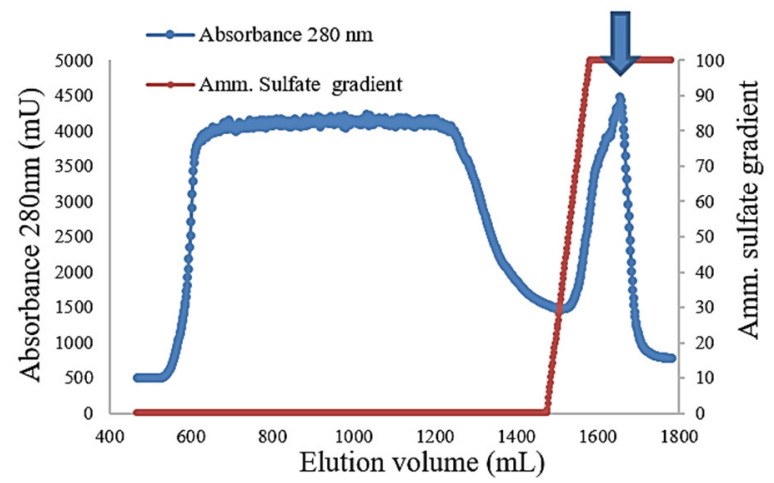

$\mathrm{D}$

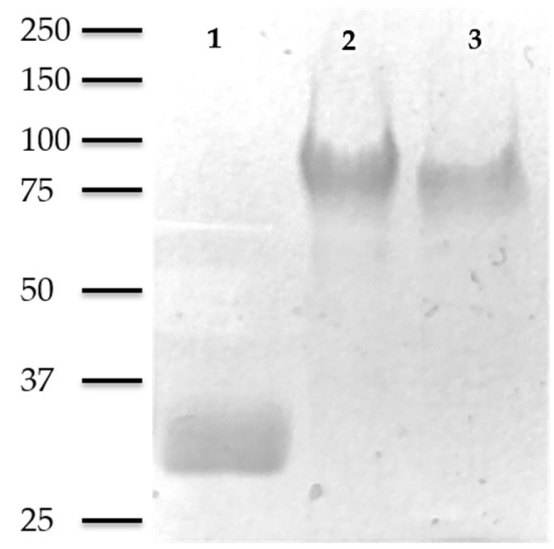

Figure 2. (A) Analysis of the expression of the three LPMO variants by SDS-PAGE. Proteins were produced in a 5-L bioreactor using Basal Salts Medium for 4 days. Lane 1: TamAA9A-CD; Lane 2: TamAA9-WT; Lane 3: TamAA9-CBM. (B) and (C) Two-step chromatographic purification of LPMOs variants from T. amestolkiae. The example describes the purification of TamAA9A-WT. (B) Hydrophobic interaction chromatography using an ammonium sulfate gradient for protein elution. (C) Anion-exchange chromatography, using a $\mathrm{NaCl}$ gradient for protein elution. Peaks containing LPMO activity are marked with arrows. (D) Purified LPMO variants: Lane 1, TamAA9A-CD; Lane 2, TamAA9A-CBM; Lane 3, TamAA9A-WT.

\subsection{Comparative Physicochemical Properties of TamAA9A Variants. Circular Dichroism and Thermostability}

The molecular masses of the three variants, determined by SDS-PAGE, showed that all of them are glycosylated proteins, as reported for other recombinant proteins expressed in P. pastoris [39]. TamAA9A-CD showed a molecular mass close to $30 \mathrm{kDa}$ (its theoretical mass was $24 \mathrm{kDa}$ ), which is consistent with $20 \%$ glycosylation. On the other hand, TamAA9A-WT and TamAA9A-CBM were massively glycosylated. The theoretical molecular masses for these variants ( $32 \mathrm{kDa}$ and $34 \mathrm{kDa}$, respectively) contrasted with the empirical determinations (about 75-100 kDa), which implies around 150\%-200\% glycosylation (Figure 2D). These results suggest that additional glycosylation occurs in the "linker-like" region (which is absent in the TamAA9A-CD variant). Although such a high glycosylation degree is not common in other recombinant fungal LPMOs, the LPMO9H from Heterobasidion irregulare, also expressed in P. pastoris, was shown to have similar characteristics [40]. Analysis with NetOGlyc 4.0 indicated that the "linker-like" region of TamAA9A harbors 28 potential 
glycosylation sites, while the catalytic domain has only four. Enzymatic deglycosylation (of $\mathrm{N}$-gylcosylation sites) using Endo $\mathrm{H}$ of the three variants (Figure S4) only showed a small reduction in protein mass, suggesting that most residues should be O-glycosylated, since enzymatic $\mathrm{O}$-deglycosylation is not very efficient compared to $\mathrm{N}$-deglycosylation [41].

Temperature and $\mathrm{pH}$ optima are fundamental parameters for an enzyme to be considered for industrial hydrolysis of lignocellulosic biomass. Generally, the biochemical characterization of LPMOs has been difficult due to the lack of easy methods to detect its activity [21]. The fact that the TamAA9A variants are able to oxidize 2,6-DMP made their characterization more feasible. First, the 24-h stability at $\mathrm{pH}$ values of $2-10$ were analyzed at $4{ }^{\circ} \mathrm{C}$, showing that all the variants had similar profiles, maintaining around $80 \%$ activity in the $\mathrm{pH}$ range of $4-7$, and losing activity out of this range (Figure S5).

The three LPMO variants exhibited good thermostability for saccharification, which is usually conducted at $50{ }^{\circ} \mathrm{C}$. However, while the $\mathrm{T}_{50}$ values of TamAA9A-WT and TamAA9A-CD were $76.1^{\circ} \mathrm{C}$ and $74.4^{\circ} \mathrm{C}$, respectively, the $T_{50}$ of TamAA9A was around $20^{\circ} \mathrm{C}$ lower $\left(57.9^{\circ} \mathrm{C}\right)$. The reduced thermal tolerance of TamAA9A-CBM suggests that the CBM has a negative effect on its thermal stability. Considering that 2,6-DMP can be easily oxidized by different agents, including the copper released after LPMO inactivation, we decided to confirm the thermostability of the different proteins by circular dichroism, as previously reported for other LPMOs [42]. The change in the stability of the secondary structure started at about $60{ }^{\circ} \mathrm{C}$, and it can be considered that all the variants lost their secondary structure at $75^{\circ} \mathrm{C}$ (Figure S6). After adjusting to a sigmoidal equation, the transition midpoint temperature (Tm) was $67.7^{\circ} \mathrm{C}$ for TamAA9A-WT, $67.6^{\circ} \mathrm{C}$ for TamAA9A-CD, and $57.8^{\circ} \mathrm{C}$ for TamAA9A-CBM. These results confirmed the lower thermotolerance of the chimeric variant with the CBM and show that, even though the enzymes can still oxidize 2,6-DMP at a higher temperature, the unfolding of secondary structures begins a little earlier than calculated by determining the $T_{50}$, especially for TamAA9A-WT and TamAA9A-CD.

Thermotolerance has been explored in other AA9 LPMOs. That is the case for LPMO9A from Thermoascus auriantiacus (TaLPMO9A), which retains $72 \%$ activity after a $45 \mathrm{~min}$ incubation at $100{ }^{\circ} \mathrm{C}$ [43]. The catalytic domains of TamAA9A and TaLPMO9A share a high sequence similarity, which could be related to their good thermal stabilities. Moreover, the thermostability of other LPMOs of the AA9 family, like those from Scytalidium thermophilum, Malbranchea cinnamomea, Myceliophthora thermophila [44,45], or Talaromyces cellulolyticus [46] are similar to that determined for TamAA9A. However, the most thermostable LPMOs are the bacterial LPMOAA10s found in a compost metagenome (mgLPMO10), with a melting temperature of $83{ }^{\circ} \mathrm{C}$ [47]. Despite this, due to the combination of thermostability and good $\mathrm{pH}$ tolerance of T. amestolkiae LPMO variants, we postulate they may be promising catalysts for lignocellulosic biomass valorization, since they are stable at the operational temperature used in industrial saccharification, where substrates are usually pretreated with alkali or diluted acid [48].

\subsection{Substrate Specificity and Binding to Cellulose}

As mentioned above, the discovery of the peroxygenase-like capacity of LPMOs allowed the use of $\mathrm{H}_{2} \mathrm{O}_{2}$ as a co-substrate for the oxidation of target compounds that produce detectable chromogenic molecules. This can be exploited for the oxidation of 2,6-DMP to coerulignone in the presence of $\mathrm{H}_{2} \mathrm{O}_{2}$, which can be detected at $469 \mathrm{~nm}$ [22,38]. The reaction was followed at concentrations of 1.25-100 mM 2,6-DMP and 0.02-20 mM $\mathrm{H}_{2} \mathrm{O}_{2}$, and the use of higher substrate concentrations produced strong enzyme inactivation. By using this method, the kinetic constants for both 2,6-DMP and $\mathrm{H}_{2} \mathrm{O}_{2}$, were determined. 2,6-DMP $K_{\mathrm{m}}$ measurements were performed by setting the $\mathrm{H}_{2} \mathrm{O}_{2}$ concentration at $2 \mathrm{mM}$, and for $\mathrm{H}_{2} \mathrm{O}_{2} K_{\mathrm{m}}$ measurements, the 2,6-DMP concentration was fixed at $10 \mathrm{mM}$ (Table 1). The three variants of TamAA9A have better kinetic constants, with a higher affinity (lower $K_{\mathrm{m}}$ ) and $k_{\text {cat }}$ values for both substrates than those detected for the LPMO from N. crassa [22], when performing the reaction at $\mathrm{pH} 6$. 
Regarding the three LPMO variants of T. amestolkiae, TamAA9A-WT and TamAA9ACD were shown to have very similar activity and substrate specificity, while TamAA9ACBM displayed three-fold less activity in the kinetics of 2,6-DMP, and a worse $K_{\mathrm{m}}$ in the kinetics of $\mathrm{H}_{2} \mathrm{O}_{2}$. This is consistent with the reduced thermostability observed for this enzyme, and is a sign that, probably, the addition of the CBM affected the activity of the enzyme and even its correct folding. Additions or eliminations of CBMs have been reported to alter the enzymatic properties of some glycosyl hydrolases [49] and LPMOs. For example, deletion of the CBMs of two AA10 LPMOs halved their activity on crystalline cellulose and PASC $[50,51]$, and removal of the CBMs of the LPMOs from the fungi Podospora anserina and $N$. crassa reduced their activity and, interestingly, misbalanced their regioselectivity $[52,53]$. In any case, as it has been postulated before, the need to conduct a detailed analysis of the role of CBMs in LPMO action is evident [17].

Table 1. Kinetic constants of TamAA9A-WT, TamAA9A-CD, and TamAA9A-CBM for $\mathrm{H}_{2} \mathrm{O}_{2}$ and 2,6-DMP.

\begin{tabular}{ccccc}
\hline Enzyme & Substrate & $\boldsymbol{K}_{\boldsymbol{m}}(\mathbf{m M})$ & $\boldsymbol{k}_{\text {cat }}\left(\mathbf{s}^{-\mathbf{1}}\right)$ & $\boldsymbol{k}_{\text {cat }} / \boldsymbol{K}_{\boldsymbol{m}}\left(\mathbf{s}^{-\mathbf{1} / \mathbf{m M})}\right.$ \\
\hline \multirow{2}{*}{ TamAA9A-WT } & 2,6-DMP & $109.8 \pm 0.5$ & $0.68 \pm 0.03$ & 0.006 \\
& $\mathrm{H}_{2} \mathrm{O}_{2}$ & $0.28 \pm 0.01$ & $0.14 \pm 0.01$ & 0.501 \\
\hline \multirow{2}{*}{ TamAA9A-CD } & $2,6-\mathrm{DMP}$ & $87.7 \pm 0.7$ & $0.96 \pm 0.04$ & 0.011 \\
& $\mathrm{H}_{2} \mathrm{O}_{2}$ & $0.31 \pm 0.02$ & $0.17 \pm 0.01$ & 0.548 \\
\hline \multirow{2}{*}{ TamAA9A-CBM } & $2,6-\mathrm{DMP}$ & $85.68 \pm 0.7$ & $0.53 \pm 0.02$ & 0.003 \\
& $\mathrm{H}_{2} \mathrm{O}_{2}$ & $1.03 \pm 0.06$ & $0.25 \pm 0.03$ & 0.135 \\
\hline
\end{tabular}

In order to determine if the three LPMO variants interact with crystalline cellulose, adsorption tests were performed. Surprisingly, none of the variants bound significantly to crystalline cellulose, not even the TamAA9A-CBM chimera, which has a cellulose binding domain that is functional in a $\beta$-glucosidase from the same fungus [28]. The fact that none of these LPMOs can bind to crystalline cellulose is intriguing and should be explored in the future. Other fungal LPMOs have demonstrated their ability to bind to crystalline cellulose even lacking a CBM, as is the case for LPMO9F from N. crassa [15].

\subsection{Phylogeny, and Homology Modeling of TamAA9A}

To analyze the structural features of the wild-type LPMO from T. amestolkiae, a molecular model was built as described by below. Regarding the catalytic domain, present in the three variants, the model revealed an overall structure similar to those from other AA9LPMOs. Its fold consisted of a $\beta$-sandwich with two $\beta$-sheets, a total of eight $\beta$-strands (four per sheet) and three loops (Figure $3 \mathrm{~A}$ ). The protein contained two putative disulfide bonds between Cys56-Cys178 and Cys97-Cys101.

The first one is conserved among AA9s, connecting the L2 to the eighth $\beta$-strand, and the second one occurs in many AA9LPMOs but is not fully conserved. The histidine brace where the catalytic copper is coordinated (Figure 3B) is formed by His1 and His 85 in the equatorial plane, and the axial Tyr175 residue is buried in the structure. Concerning the environment around the copper atom, TamAA9A showed a flat surface typical for AA9LPMOs able to act on crystalline substrates, without ridges or protuberant loops. LPMOs show a large variance in their substrate-binding surfaces located in the loops that connect the strands of the $\beta$-sandwich (highlighted in Figures $3 \mathrm{C}$ and 4), defined as L2, L3 (only present in C4 oxidizers), LS (loop short) and LC (C-terminal loop) [54]. Similarly to other C1-C4 oxidizers, such as TaAA9A, the LPMO9A from T. amestolkiae contains the loops L2, LS and LC. 

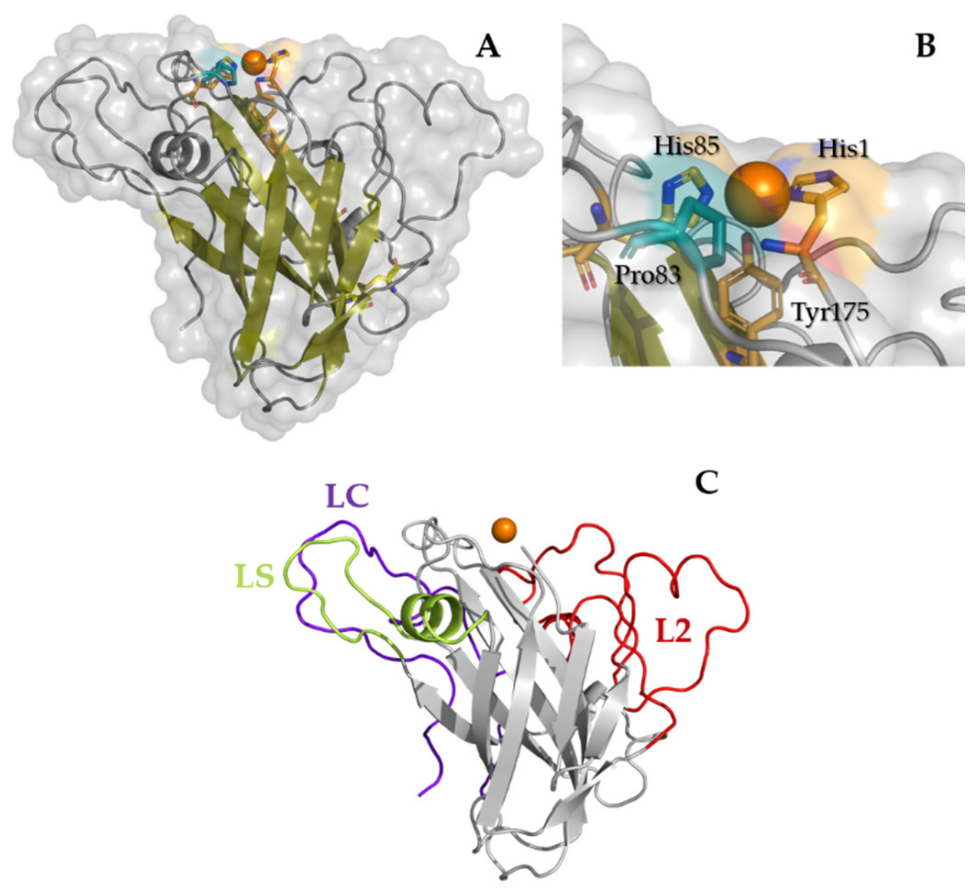

Figure 3. Homology model of TamAA9A built in SwissModel. The overall fold of TamAA9A is a conserved $\beta$-sandwich and displays a flat substrate-binding surface. (A) Residues coordinating the catalytic copper are displayed in bright orange, disulfide bonds in yellow and the putative residue controlling the accessibility to the copper and regioselectivity in deep teal. (B) Zoom of the catalytic center. (C) The loops interconnecting the strands that define the substrate-binding surface are: red, L2; green, LS; purple, LC.

Regarding the structural elements that have been proposed to control the regioselectivity in AA9s, TamAA9A contains a Pro83 in agreement with other C1-C4 oxidizers, which would provide intermediate access to the axial position of copper among strict $\mathrm{C} 1$ oxidizers (with a Tyr in the homologous position) or strict C4 oxidizers (showing an Ala) [52]. However, this function is under debate and should be explored carefully, since mutagenesis studies in PcAA9D point to a more important role for the hydrophobic residues exposed in the substrate-binding surface [55].

On the other hand, the linker-like sequence from TamAA9A-WT was modeled by AlphaFold2.0 or RoseTTAFold as an extended and unstructured C-t, with poor accuracy in both cases (Figure S2). The model of the chimeric variant with a CBM, presents both domains accurately folded and bound by the linker, which is displayed either as a part of the catalytic AA9 domain by AlphaFold2.0 or as a separate domain by RoseTTAFold.

Finally, a protein phylogeny was analyzed using the sequences of characterized AA9 LPMOs available in the CAZy database. The resulting cladogram placed TamAA9A in the C1/C4 oxidizers clade (Figure 5), with the LPMOs from T. aurantiacus and Aspergillus tamarii being its closest homologues. To the best of our knowledge, the regioselectivity of fungal LPMOs from Penicillium or Talaromyces species has not been previously analyzed, but all the phylogenetic analyses usually place them as $\mathrm{C} 1 / \mathrm{C} 4$ oxidizers [56]. To confirm the regioselectivity of TamAA9A, the reaction products were characterized by HPAEC-PAD. 

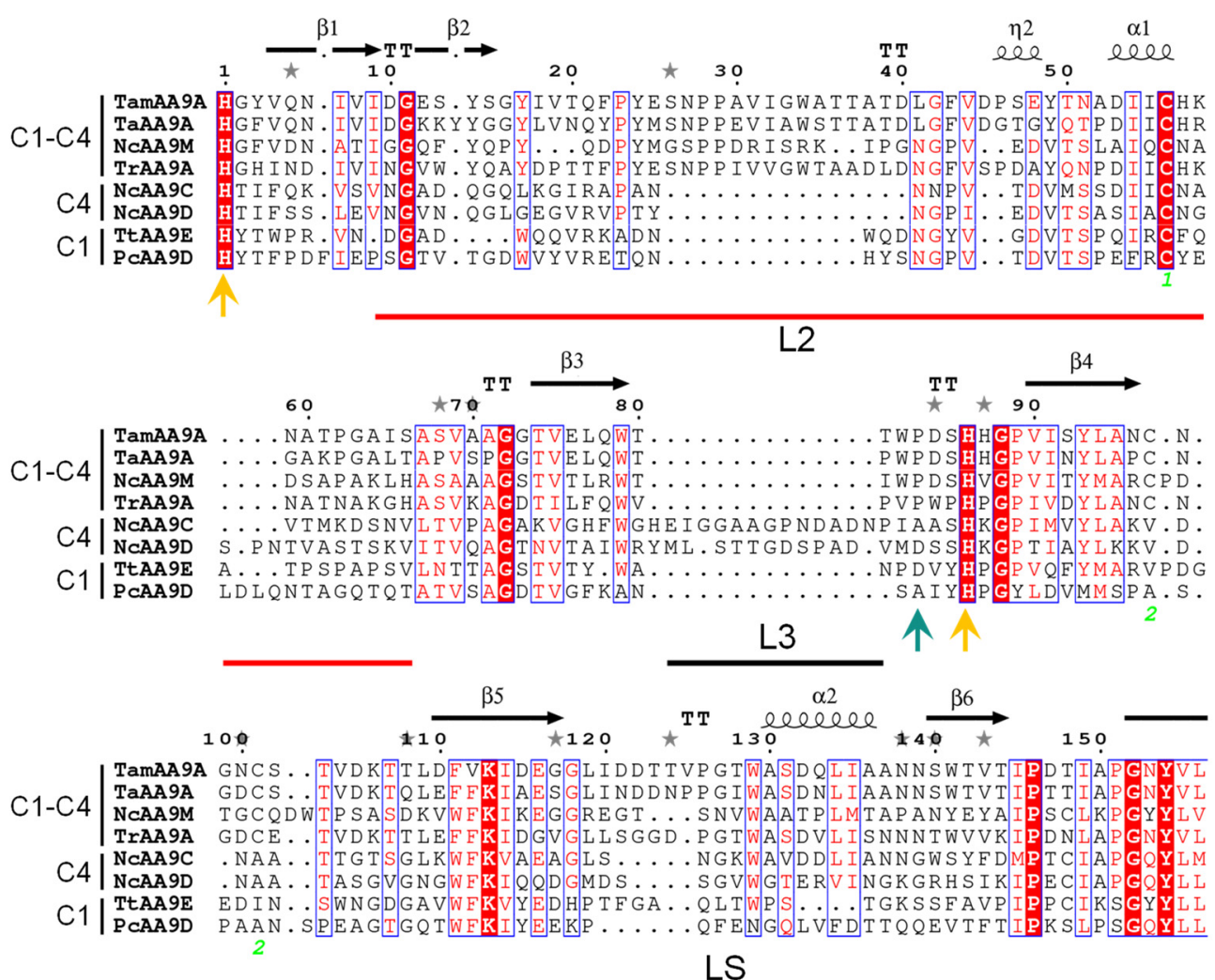

LS

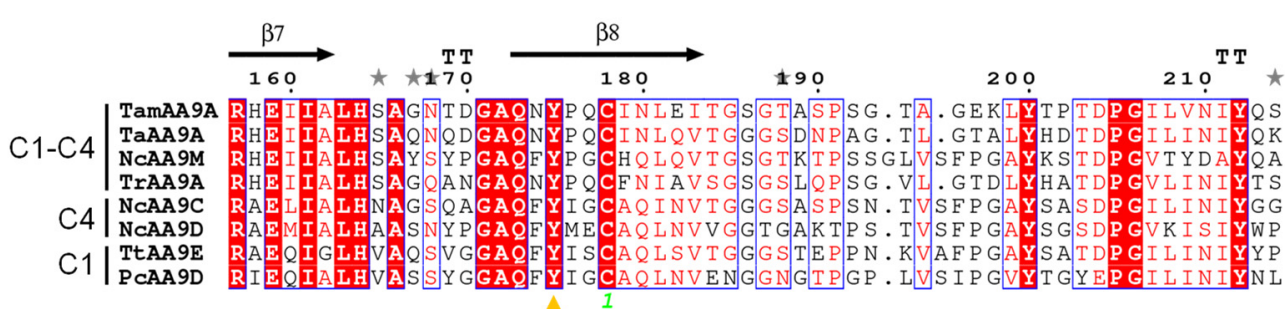

LC

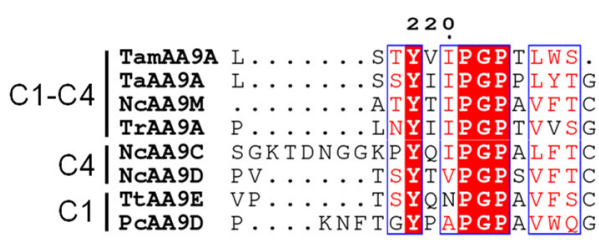

Figure 4. Sequence alignment of selected LPMOs. White in red background: fully conserved residues; blue frames: more than $70 \%$ of the residues aligned have similar properties (red residues on a white background). Yellow arrows indicate residues coordinating the catalytic copper. The green arrow shows the putative residue that controls regioselectivity in AA9s. Green numbers mark disulfide bonds. The loops interconnecting the strands of the $\beta$-sandwich are marked as L2, L3, LS and LC. Alignment was built with AA9 LPMOs from Thermoascus auranticus (TaAA9A), Neurospora crassa (NcAA9M, C and D), Trichoderma reesei (TrAA9A), Thermothielavioides terrestris (TtAA9E), and Phanerochaete chrysosporium (PcAA9D). 


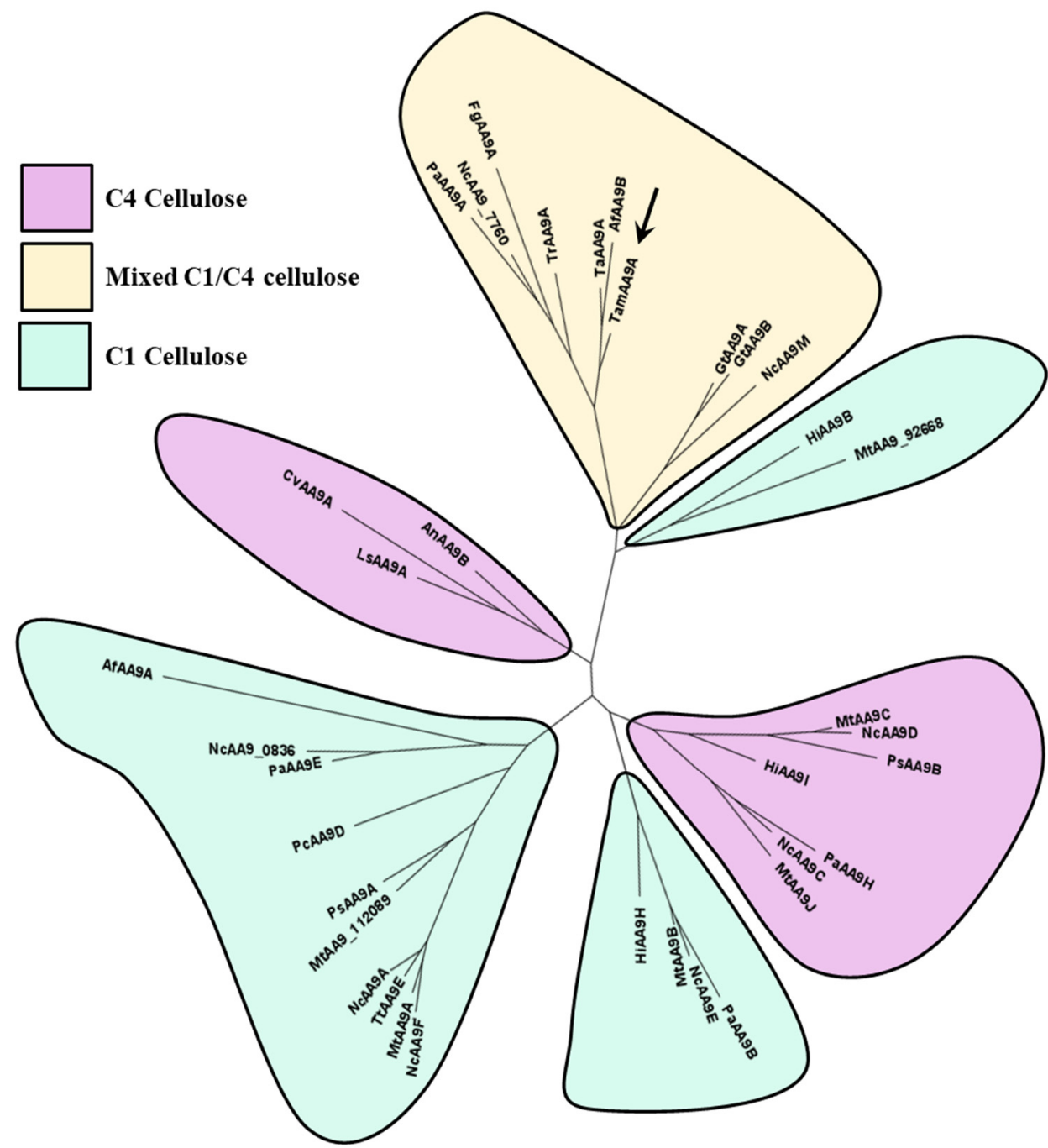

Figure 5. Cladogram built using the characterized AA9s in CAZy, after sequence alignment with MAFFT and tree building with PhyML. Af, Aspergillus fumigatus; An, Aspergillus nidulans; At, Aspergillus tamarii; $\mathrm{Cv}$, Collariella virescens; Fg, Fusarium graminearum; Gt, Gloeophyllum trabeum; Hi, Heterobasidion irregulare; Ls, Lentinus similis; Mt, Myceliophtora thermophila; Nc, Neurospora crassa; Pa, Podospora anserina; Pc, Phanerochaete chrysosporium; Ps, Pestalotiopsis sp.; Ta, Thermoascus auranticus; Tam, Talaromyces amestolkiae; Tr, Trichoderma reesei; Tt, Thermothielavioides terrestris.

\subsection{PASC and CMC Degradation Analysis by HPAEC-PAD}

For experimental confirmation of the activity and regioselectivity of the wild-type LPMO TamAA9A-WT from T. amestolkiae, the release of native and oxidized cellooligosaccharides was qualitatively studied using PASC and CMC as substrates, and $1 \mathrm{mM}$ ascorbic acid as the electron donor. Samples of these reactions were analyzed by HPAEC -PAD. By using this technique, reaction products could be separated according to their oxidation degree and length. In the conditions used in this work, monooxidized products elute first, followed by dioxidized products. The chromatograms of samples from enzymatic treatments of PASC and CMC are depicted in Figure 6A,B, respectively. Native cello-oligosaccharides with a degree of polymerization (DP) from two to five eluted in the first place, between 30 and $40 \mathrm{~min}$. Then, small peaks that may correspond to C1-oxidized or C4-oxidized cello-oligosaccharides were detected after around $60 \mathrm{~min}$, and later, at retention times of about $90 \mathrm{~min}$, a final series of peaks eluted. These usually correspond to doubly oxidized products, which confirms the C1/C4 regioselectivity of TamAA9A-WT. 
The chromatograms showed profiles similar of those observed for other treatments with LPMOs [13].

A
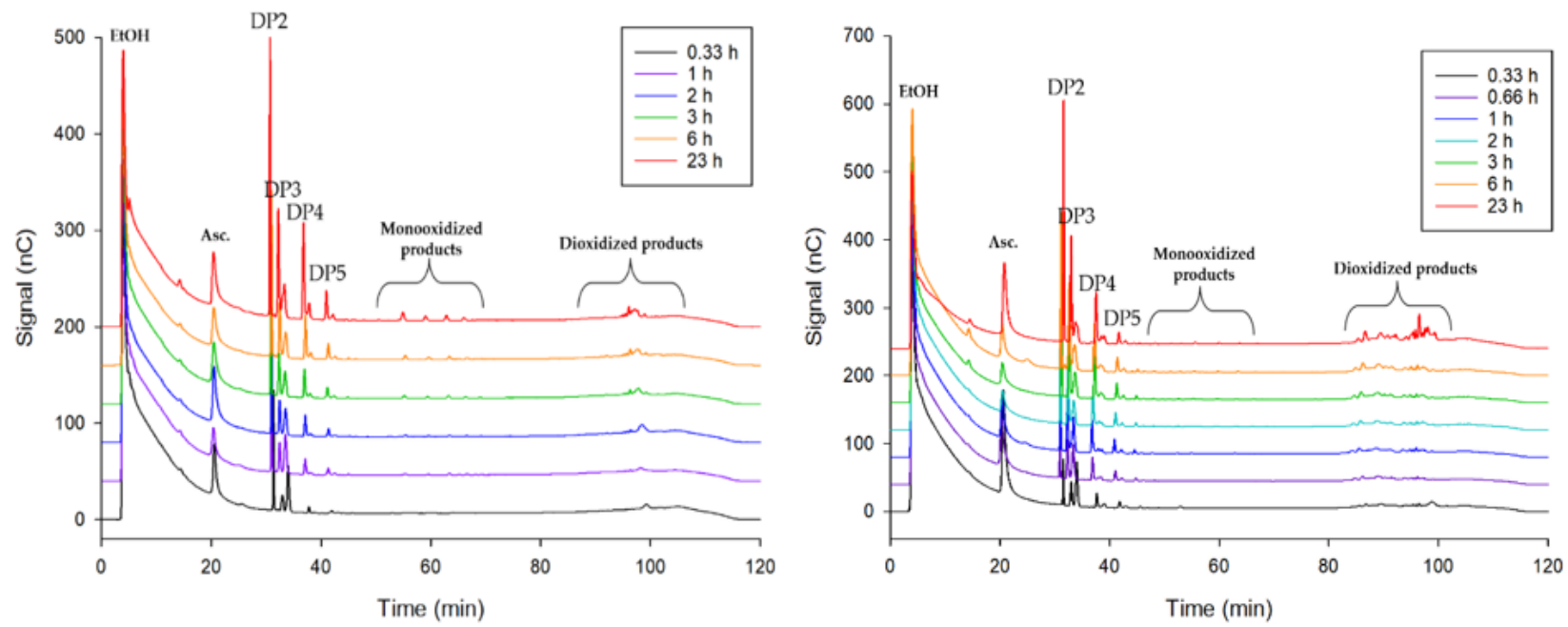

Figure 6. (A) HPAEC-PAD elution profile of PASC degradation samples after incubation with TamAA9A-WT. Reaction conditions: $1 \%(w / v)$ phosphoric acid swollen cellulose (PASC), $100 \mathrm{mM}$ phosphate buffer ( $\mathrm{pH}$ 6.0), $1 \mathrm{mM}$ ascorbic acid, $20 \mu \mathrm{g} / \mathrm{mL}$ of LPMO, and $30{ }^{\circ} \mathrm{C}$. (B) HPAEC-PAD elution profile of CMC degradation samples after incubation with TamAA9A-WT. Reaction conditions: 1\% (w/v) carboxymethyl cellulose (CMC), $100 \mathrm{mM}$ phosphate buffer (pH 6.0), $1 \mathrm{mM}$ ascorbic acid, $20 \mu \mathrm{g} / \mathrm{mL}$ of LPMO, and $30^{\circ} \mathrm{C}$. Structures of the potentially obtained products can be seen in the Figure 1 in the introduction section.

Differences between PASC and CMC degradation can be observed mainly in the size of the peaks eluting at about $60 \mathrm{~min}$ (which is clearly more intense in PASC), and in the region of products with a double oxidation, that present many more peaks in CMC degradation. Moreover, the big difference found in the size of the peaks of native oligosaccharides compared with those of the oxidized species could be related to the spontaneous formation of native oligosaccharides, as explained by Westereng et al. [13]. In any case, besides the doubly oxidized products, the chromatogram showed peaks corresponding to oxidized products only in $\mathrm{C} 1$ or $\mathrm{C} 4$, which merits further investigation. It should be remarked that, as analyzing the regioselectivity of AA9 LPMOs produced by species from Penicillium or Talaromyces is a difficult task, authors usually do not report the $\mathrm{C} 1$ or $\mathrm{C} 4$ preference of the enzymes $[46,56,57]$. This work is expected to lay the foundations for developing further research in the AA9LPMOs produced by these genera, well known for their ability to secrete a high number of GHs involved in lignocellulose degradation, and to establish the role of these oxidative enzymes in plant biomass valorization.

\subsection{Effect of TamAA9A in Saccharification of Cellulosic Substrates}

The conversion of plant residues to glucose is a crucial step in the production of biofuels from lignocellulosic biomass. To determine if the three variants of T. amestolkiae LPMOs can improve the saccharification yield, four different substrates were assayed: (i) crystalline cellulose, (ii) PASC, (iii) wheat straw slurry (steam explosion pretreated), and (iv) brewers spent grain. After pretreatment of the different materials with the LPMOs (16 h), no glucose release was detected.

Then, the samples were treated with a cellulolytic commercial cocktail (Celluclast $1.5 \mathrm{~L}$ ), following the glucose released for $40 \mathrm{~h}$. In all cases, the three LPMO variants increased the final saccharification yield (Figure 7). Crystalline cellulose and PASC are cellulosic model substrates in which LPMOs should act without being inhibited by other components of the reaction mixture. The best saccharification yields were obtained with TamAA9A-WT, that increased the glucose release by around $20 \%$ for PASC and $27 \%$ 
for crystalline cellulose, in a significantly different manner, when compared with control samples not treated with LPMOs (Figure 7A,B). TamAA9A-CD was less efficient, increasing the yield of glucose by $13 \%$ for both substrates, and TamAA9A-CBM only enhanced this yield by $2 \%-3 \%$ (which was expected, since its activity was three times lower on 2,6-DMP oxidation, which may imply that the LPMO is being be inhibited by the CBM). Thus, the wild-type protein was the most effective against these substrates, and it was especially relevant in the saccharification of crystalline cellulose, overpassing by $15 \%$ the values obtained using TamAA9A-CD, while the enhancement observed for the other substrate was around $7 \%-9 \%$. Although further research is needed, these data suggest that the "linker-like" region of the wild-type enzyme helps in the degradation of pure crystalline cellulose.
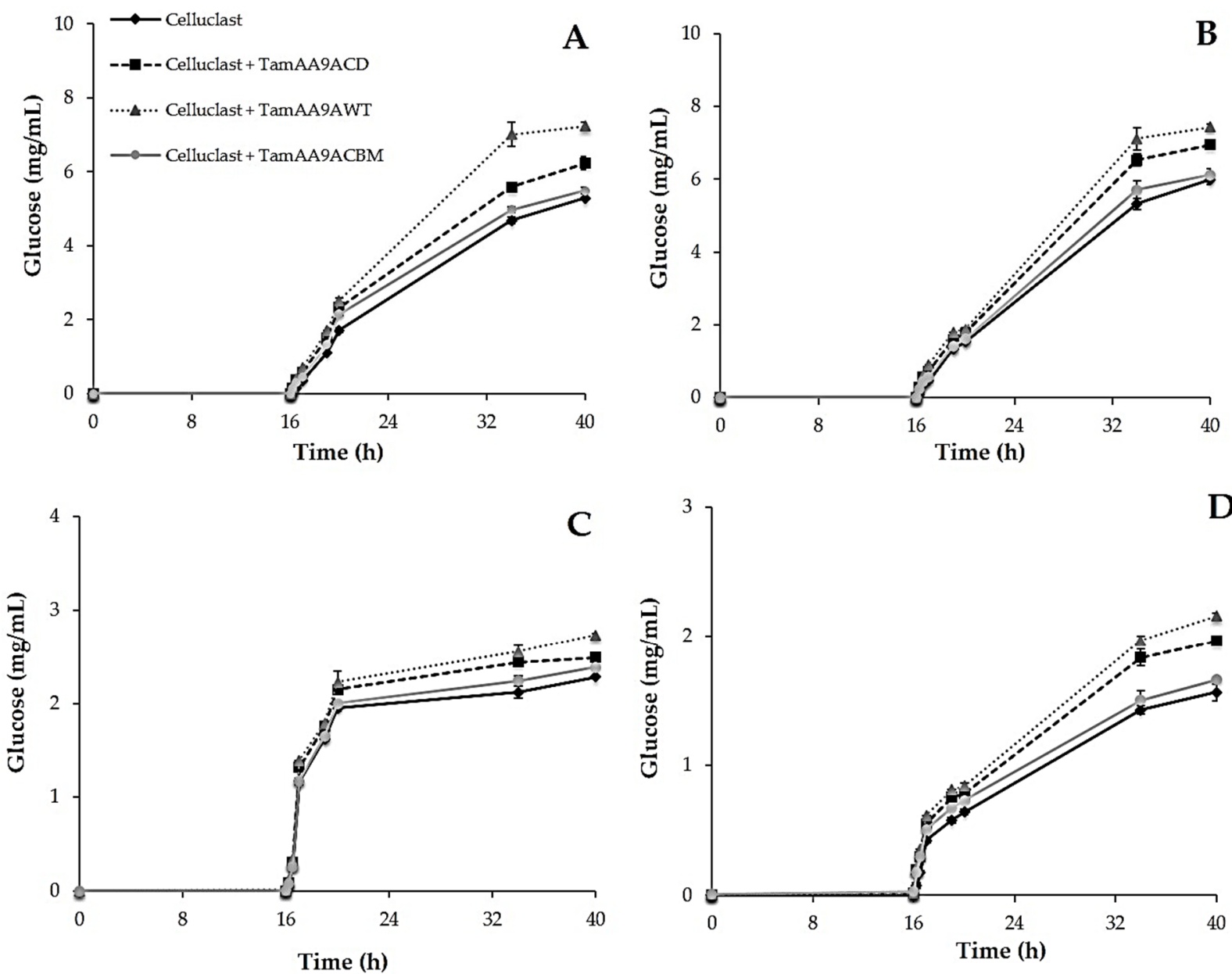

Figure 7. Glucose released by saccharification of different substrates pretreated for $16 \mathrm{~h}$ with TamAA9A-WT, TamAA9A-CD, or TamAA9A-CBM. A $20 \mathrm{mg}$ amount of each material was incubated for $40 \mathrm{~h}$ with $1 \mathrm{U}$ of $\beta$-glucosidase activity of Celluclast $1.5 \mathrm{~L}$, at $50{ }^{\circ} \mathrm{C}$ and 1,200 rpm. (A) Crystalline cellulose. (B) PASC. (C) Wheat straw slurry. (D) Brewers spent grain. All reactions were performed in triplicate.

Finally, we evaluated if LPMOs were able to act on lignocellulose substrates, which are the materials used in real industrial processes (Figure 7C,D). Again, pretreatment with the wild-type LPMO produced the best improvements (with statistically significant differences) in the saccharification yields of these materials. The most important effect was observed for brewers spent grain, with an enhancement of the glucose released of $28 \%$ against the $17 \%$ determined for wheat straw slurry. It should be noticed that the slurry represents a complex and recalcitrant material obtained by the steam explosion of wheat straw. This severe physicochemical pretreatment is known to produce compounds that may act as 
inhibitors of LPMO activity. The improvements in the saccharification of these substrates when pretreated with TamAA9A-CD and TamAA9A-CBM amounted to $18 \%$ and $5 \%$ for brewers spent grain, and $8 \%$ and $4 \%$ for wheat straw slurry, respectively.

The moderate increase in the saccharification yields of all the materials assayed by pretreatment with LPMO variants of T. amestolkiae is in agreement with the results obtained with other fungal LPMOs $[45,58,59]$, that enhanced saccharification of bagasse, rice straw, sorghum stover or pretreated oak by $15 \%-30 \%$.

\section{Materials and Methods}

\subsection{Microorganism and Culture Conditions}

The T. amestolkiae A795 strain is deposited in the IJFM collection, at the Centro de Investigaciones Biológicas Margarita Salas (Madrid, Spain). The fungus was grown on PDA (potato dextrose agar) plates at $28{ }^{\circ} \mathrm{C}$ and maintained at $4{ }^{\circ} \mathrm{C}$. For RNA extraction, the fungus was cultured in Mandels medium [28], with 1\% crystalline cellulose (Merck, Darmstadt, Germany) for enzyme induction. Escherichia coli DH5 $\alpha$ was selected for plasmid propagation. After transformation, it was grown at $37^{\circ} \mathrm{C}$ on LB agar plates $(10 \mathrm{~g} / \mathrm{L}$ tryptone, $5 \mathrm{~g} / \mathrm{L}$ yeast extract, $10 \mathrm{~g} / \mathrm{L} \mathrm{NaCl}$, and $15 \mathrm{~g} / \mathrm{L}$ agar) containing $25 \mathrm{mg} / \mathrm{L}$ zeocin for the selection of recombinant clones. The heterologous expression of TamAA9A was carried out using the P. pastoris $\mathrm{X} 33$ strain and the procedure was adapted from the EasySelect ${ }^{\mathrm{TM}}$ Pichia Expression Kit manual (Invitrogen, Waltham, MA, USA). The strain was cultivated on YPD plates (10 g/L yeast extract, $20 \mathrm{~g} / \mathrm{L}$ peptone, $20 \mathrm{~g} / \mathrm{L}$ glucose and $10 \mathrm{~g} / \mathrm{L}$ agar). Transformants were selected and cultivated on YPD containing $100 \mathrm{mg} / \mathrm{L}$ zeocin and cultured $2-5$ days at $28^{\circ} \mathrm{C}$. Recombinant protein was produced in YEPS medium $(20 \mathrm{~g} / \mathrm{L}$ peptone, $10 \mathrm{~g} / \mathrm{L}$ yeast extract, $10 \mathrm{~g} / \mathrm{L}$ sorbitol, and $100 \mathrm{mM}$ potassium phosphate buffer, $\mathrm{pH}$ 6), with daily addition of $10 \mathrm{~mL} / \mathrm{L}$ of methanol as an inducer. It was also performed using 5-L fermenters with a basal salt medium (phosphoric acid $26.7 \mathrm{~mL} / \mathrm{L}$, calcium sulfate $0.93 \mathrm{~g} / \mathrm{L}$, potassium sulfate $18.2 \mathrm{~g} / \mathrm{L}$, magnesium sulfate $-7 \mathrm{H}_{2} \mathrm{O} 14.9 \mathrm{~g} / \mathrm{L}$, potassium hydroxide $4.13 \mathrm{~g} / \mathrm{L}$, glycerol $40.0 \mathrm{~g} / \mathrm{L}$ ) according to Invitrogen Pichia Fermentation Process Guidelines (Invitrogen, Waltham, MA, USA).

\subsection{Identification of the T. amestolkiae LPMO Gene, Nucleic Acid Isolation, Cloning and Expression in P. pastoris}

A putative LPMO nucleotide sequence, annotated as AA9A in the T. amestolkiae genome (GenBank accession no. MIKG00000000) [24], was identified and analyzed using the SignalP 5.0 server to identify potential signal peptides. To amplify this putative LPMO sequence (named as TamAA9A) and to detect the presence of introns, RNA was extracted with Trizol (Ambion, Waltham, MA, USA) [60] from 7-day old T. amestolkiae cultures growing on $1 \%$ crystalline cellulose as a carbon source. After RNA extraction, the isolated transcripts were transformed into cDNA using the Superscript II Reverse Transcriptase RT-PCR kit (Invitrogen, Waltham, MA, USA), according to the manufacturer's instructions. Finally, PCR amplifications were performed in a thermocycler Mastercycler pro S (Eppendorf, Hamburg, Germany). Primers for TamAA9A amplification were designed by analyzing the nucleotide sequence. Restriction sites for XhoI and NotI (New England Biolabs, MA, USA) were included in the forward and reverse primers, respectively (LPMOFWXHOI: 5'-ATCTCGAGAAAAGACATGGTTATGTGCAAAACATCG-3', and LPMORVNOTI: $5^{\prime}$-ATGCGGCCGCTTAAAAGACAGTGGTGGTGATGA- $3^{\prime}$ ). The PCR protocol was carried out as follows: initial denaturation at $95{ }^{\circ} \mathrm{C}$ for $5 \mathrm{~min}$, followed by 30 cycles of amplification: denaturation at $95^{\circ} \mathrm{C}$ for $45 \mathrm{~s}$, primer annealing at $55^{\circ} \mathrm{C}$ for $45 \mathrm{~s}$, and elongation at $72{ }^{\circ} \mathrm{C}$ for $2 \mathrm{~min}$, with $72{ }^{\circ} \mathrm{C}$ for $10 \mathrm{~min}$ as the final step. The PCR product obtained was introduced in the pPICZ $\alpha$ vector (Invitrogen, Waltham, MA, USA), and cloned into E. coli DH5 $\alpha$, where it was sequenced. Different plasmids were designed for recombinant production of TamAA9A. On the one hand, the protein was expressed using the $\alpha$-factor signal peptide. To do so, the complete T. amestolkiae protein sequence (including the natural "linker-like" region) was cloned into pPICZ $\alpha$, after PCR 
amplification of the cDNA, with the primers LPMOFWXHOI and LPMORVNOTI. On the other hand, the LPMO was expressed using its native signal peptide. For this purpose, three pPICZ-derived plasmids were designed, containing either the native LPMO sequence, only the catalytic domain of the LPMO, or the native enzyme with a cellulose binding domain. This CBM belongs to BGL-2, a previously characterized $\beta$-glucosidase from the same fungus [28]. This sequence (acacagaccccgtatggacagtgtggtggacagggctggagcggtcctacagtttgttcatccggctggacttgtaaggtgacgaatcagtggtattctcaatgcctacaatag) was added after the "linker-like" region and constructed by General Biosystems (Durham, NC, USA). All the constructions were transformed into P. pastoris X-33 by the lithium chloride method (according to manufacturer's instructions), after linearization with SacI (New England Biolabs, MA, USA) to increase the efficiency. Transformed colonies were grown on YPD medium plates with zeocin as a selection marker.

\subsection{Production and Purification of LPMO}

Selected clones were grown overnight in $250 \mathrm{~mL}$ flasks with $50 \mathrm{~mL}$ of YPD medium at $28^{\circ} \mathrm{C}$ and $250 \mathrm{rpm}$. Then, $16 \mathrm{~mL}$ was used to inoculate a $2 \mathrm{~L}$ flask containing $400 \mathrm{~mL}$ of YEPS medium. Cultures were incubated at $28^{\circ} \mathrm{C}$ and $250 \mathrm{rpm}$ for 5 days with a daily addition of $10 \mathrm{~mL} / \mathrm{L}$ methanol. The enzyme secretion of positive clones was monitored by measuring the protein concentration in the culture supernatants using Bradford reagent (Bio-Rad, Hercules, CA, USA) and comparing it with non-transformed strains used as negative controls. TamAA9A production was further confirmed by SDS-PAGE. Enzyme production was performed using a BioFlo 120 (Eppendorf, Hamburg, Germany) bioreactor and the procedure was adapted from the Pichia Fermentation Process Guidelines (Invitrogen).

Enzymes were further produced in a 5-L BioFlo 120 (Eppendorf, Hamburg, Germany) bioreactor with a starting volume of $3 \mathrm{~L}$ basal salt medium supplemented with $4.35 \mathrm{~mL} / \mathrm{L}$ of PTM1 trace salts (Invitrogen Pichia Fermentation Process Guidelines) and $0.1 \mathrm{mM}$ $\mathrm{CuSO}_{4}$. After sterilization, the $\mathrm{pH}$ of the medium was adjusted to 5.0 with $28 \%$ ammonium hydroxide and maintained during the fermentation. The procedure was adapted from the Pichia Fermentation Process Guidelines of Invitrogen. After the initial batch and fed-batch phase using glycerol as the carbon source, enzyme production was induced by the addition of methanol containing $12 \mathrm{~mL}$ of L-1 Pichia Trace Metal solution (PTM1) and the feed rate was adjusted to maintain a $20 \%$ oxygen saturation. Samples were taken regularly and the wet biomass, protein concentration and LPMO activity based on the oxidation of 2,6-DMP, were measured (see below). Purification of the three LPMO variants was performed using an ÄKTA Purifier FPLC system (GE Healthcare Life Sciences, Chicago, IL, USA). Cells were removed by centrifugation and the supernatant was clarified by filtration. Then, 30\% ammonium sulfate was added to the supernatant, and it was applied onto a $100 \mathrm{~mL}$ PHE-Sepharose FastFlow resin (GE Healthcare), equilibrated with 30\% ammonium sulfate in $10 \mathrm{mM}$ sodium phosphate buffer, $\mathrm{pH}$ 6.0. After binding, proteins were eluted with a linear gradient from $30 \%$ to $0 \%$ ammonium sulfate. Fractions with LPMO activity were pooled, dialyzed against $10 \mathrm{mM}$ phosphate buffer $\mathrm{pH}$ 6, and applied onto a $5 \mathrm{~mL}$ QFF HiTrap cartridge (GE Healthcare) equilibrated with the same buffer. Proteins were eluted with a $\mathrm{NaCl}$ gradient (from 0 to $0.4 \mathrm{M}$ during the $70 \mathrm{~mL}$ elution). Fractions with LPMO activity were pooled, concentrated, and protein homogeneity was confirmed by SDS-PAGE.

\subsection{Protein Quantification, Enzyme Assays and Substrate Specificity}

All the reagents for the reactions were purchased from Sigma Aldrich (Burlington, MA, USA). Purified LPMOs were saturated with copper by incubation with an equimolar concentration of $\mathrm{CuSO}_{4}$ for $1 \mathrm{~h}$ at room temperature. After this, the enzymes were dialyzed against $10 \mathrm{mM}$ phosphate buffer, $\mathrm{pH}$ 6. The protein concentration of the purified enzymes was calculated by measuring the absorbance at $280 \mathrm{~nm}$ using a Nanodrop spectrophotometer (Thermo Fisher Scientific, Waltham, MA, USA) and by the bicinchoninic acid assay (BCA) method. 
For fast detection of LPMO activity, the oxidation of 2,6-dimethoxyphenol (2,6-DMP) to coerulignone $\left(\varepsilon_{469}=53,200 \mathrm{M}^{-1} \mathrm{~cm}^{-1}\right)$ was followed spectrophotometrically [22,38]. The standard reaction was performed in $100 \mathrm{mM}$ sodium phosphate buffer $\mathrm{pH} 6$ with $10 \mathrm{mM}$ 2,6-DMP, $2 \mathrm{mM} \mathrm{H}_{2} \mathrm{O}_{2}$, and $20 \mu \mathrm{g} / \mathrm{mL}$ of each LPMO variant. An enzymatic activity of $1 \mathrm{U}$ was defined as the amount of enzyme that transforms $1 \mu \mathrm{mol}$ substrate $/ \mathrm{min}$. Kinetic constants of the purified LPMOs were determined for 2,6-DMP over a range of concentrations from $100 \mathrm{mM}$ to $1.25 \mathrm{mM}$ (concentration of $\mathrm{H}_{2} \mathrm{O}_{2}$ was set at $2 \mathrm{mM}$ ), and for $\mathrm{H}_{2} \mathrm{O}_{2}$ (in a range of concentrations from $20 \mathrm{mM}$ to $0.02 \mathrm{mM}$ ) with the concentration of 2,6-DMP fixed at $10 \mathrm{mM}$. SigmaPlot 14.0 ((Systat Software, Erkrath, Germany) was used to fit the data to the Michaelis-Menten equation and calculate the kinetic constants.

\subsection{Physicochemical Properties. Cellulose Binding. Circular Dichroism}

The LPMO variants were subjected to $\mathrm{N}$ - and $\mathrm{O}$-deglycosylation by using Endoglycosidase $\mathrm{H}$ or O-Glycosidase (Roche, Basil, Switzerland), according to the manufacturer's instructions. Differences in the molecular mass before and after deglycosylation were analyzed by SDS-PAGE electrophoresis. The possible glycosylation sites of the LPMOs were analyzed with the NetNGlyc 4.0 Server (https:/ / services.healthtech.dtu.dk/service. php?NetOGlyc-4.0, accessed on 15 December 2021).

The stability at different $\mathrm{pH}$ values was assayed using 2,6-DMP as the substrate and Britton-Robinson buffer (100 mM) in a pH range from 2 to 10 . Temperature stability was determined after incubating the enzymes for $3 \mathrm{~h}$ in $100 \mathrm{mM}$ sodium phosphate buffer $\mathrm{pH} 6$, at temperatures ranging from 40 to $95^{\circ} \mathrm{C}$, then cooling them to $4{ }^{\circ} \mathrm{C}$ for $10 \mathrm{~min}$ and then rewarming them to room temperature for $5 \mathrm{~min}$ before measuring the residual activity by the standard 2,6-DMP assay. The $\mathrm{T}_{50}$ value is defined as the temperature at which the enzyme loses $50 \%$ of its activity after $3 \mathrm{~h}$ of incubation. SigmaPlot 14.0 was used to fit the data to a sigmoidal equation. To further study the thermostability of LPMOs, they were analyzed by circular dichroism (CD) using a JASCO J-850 spectropolarimeter (Hachioji-shi, Tokyo, Japan). The conformational stability of the three LPMO variants was determined in a temperature ramp from 20 to $95^{\circ} \mathrm{C}$. The temperature was increased at a rate of $20^{\circ} \mathrm{C} / \mathrm{h}$. Protein unfolding was monitored at $220 \mathrm{~nm}$ by far-UV CD [42]. The binding affinity was evaluated using crystalline cellulose as a substrate [28]. For each purified enzyme $30 \mathrm{ng}$ was mixed with $500 \mu \mathrm{L}$ of $1 \%$ crystalline cellulose $(w / v)$ in $10 \mathrm{mM}$ sodium phosphate buffer $\mathrm{pH}$ 6. The reaction was incubated at $1,200 \mathrm{rpm}$ and $4{ }^{\circ} \mathrm{C}$ for $24 \mathrm{~h}$. Aliquots were taken at different times (10 min, 1, 2, 3 and $24 \mathrm{~h}$ ) and after centrifuging the samples for $1 \mathrm{~min}$ at $14,000 \times g$, the residual LPMO activity in the supernatants was measured.

\subsection{Phylogenetic and Protein Structure Analyses of the T. amestolkiae LPMO}

A protein cladogram was built using the information on characterized AA9 LPMOs from the CAZy database and on TamAA9A. After removal of the signal peptides and CBMs, the amino acid sequences were aligned using MAFFT [61] with the L-INS-i option. The resulting multiple sequence alignment was then used as the input for PhyML [62] to obtain the cladogram using the WAG+I+G+F model, which was revealed as the best evolutionary model for the dataset using prottest3 [63] (Whelan and Goldman (WAG) evolutionary model, with amino acid frequencies $(+\mathrm{F})$, proportion of invariant sites $(+\mathrm{I})$ and estimated shape parameter of the gamma distribution $(+\mathrm{G})$ ). The classification of $\mathrm{C1}-$ and C4-oxidizing LPMOs was based on sequence clusters as reported by [18]. A selection of C1, C4 or C1-C4 oxidizers was used to display conserved motifs using ESPript3 [64].

Models of the T. amestolkiae LPMO variants were predicted by homology-based modeling using the SwissModel server [65]. To gain insight into the "linker-like region" or the chimeric construct of TamAA9A with the CBM, models of TamAA9A-WT, TamAA9A-CD and TamAA9A-CBM were additionally built using AlphaFold2.0 [66] as implemented in the SAGA supercomputer resources at NTNU, Trondheim, Norway, or RoseTTAFold [67] as implemented in the Robetta server (https: / / robetta.bakerlab.org/, accessed on 15 De- 
cember 2021). The best model of each variant (based on per-residue estimate confidence, pLDDT for Alphafold and CA-IDDT for RoseTTAFold) was selected for analysis.

\subsection{Analysis of Degradation Products from Cellulose by High-Performance Anion-Exchange} Chromatography Coupled with Pulsed Amperometric Detection (HPAEC-PAD)

Phosphoric acid swollen cellulose (PASC), prepared as described previously [68], and carboxymethyl cellulose were used as model substrates at a concentration of $1 \%(w / v)$ for analysis of the products released by the enzymatic treatments. Both substrates were incubated for $23 \mathrm{~h}$ at $30^{\circ} \mathrm{C}$ with the different LPMO variants in $100 \mathrm{mM}$ phosphate buffer $\mathrm{pH} 6$ with $1 \mathrm{mM}$ ascorbic acid as an electron donor. Aliquots $(200 \mu \mathrm{L})$ were withdrawn at different intervals and mixed with absolute ethanol to a final ethanol concentration of $70 \%$, precipitating the residual polysaccharide. Samples were centrifuged at 10,000 rpm for $5 \mathrm{~min}$ and filtered through $0.45 \mu \mathrm{m}$ nylon filters (Cosela, Seville, Spain). Then, the samples were desiccated in a vacuum concentrator 5301 (Eppendorf, Hamburg, Germany) at $30^{\circ} \mathrm{C}$ until a volume of around $200 \mu \mathrm{L}$ was reached. Negative controls without ascorbic acid and/or LPMO were similarly treated under the same conditions. The oligosaccharides released were analyzed by HPAEC-PAD in a Dionex ICS3000 system (Dionex, Thermo Fischer Scientific Inc., Waltham, MA, USA) consisting of an SP gradient pump, an electrochemical detector with a gold working electrode and $\mathrm{Ag} / \mathrm{AgCl}$ reference electrode, and an autosampler (model AS-HV). All eluents were degassed by flushing with helium. A pellicular anion-exchange $4 \times 250 \mathrm{~mm}$ Carbo-Pack PA-100 column (Dionex, Thermo Fischer Scientific Inc., Waltham, MA, USA) connected to a $4 \times 50 \mathrm{~mm}$ CarboPac PA-100 guard column was used at $30^{\circ} \mathrm{C}$. The eluent was prepared with Milli-Q water, $\mathrm{NaOH}$ and sodium acetate. The mobile phase contained $10 \mathrm{mM} \mathrm{NaOH}$ from start to end, whilst two gradients were performed with sodium acetate. The first was an $80 \mathrm{~min}$-gradient from 0 to $60 \mathrm{mM} \mathrm{AcONa}$, and the second was from 60 to $160 \mathrm{mM}$ in $20 \mathrm{~min}$. Finally, the column was equilibrated back to the initial conditions. The chromatograms were analyzed using Chromeleon 7.2 software (Thermo Fisher, Waltham, MA, USA) and the identification of the different carbohydrates was done on the basis of commercial standards when available.

\subsection{Saccharification of Lignocellulosic Substrates}

The effect of LPMO variants on saccharification efficiency was studied using different lignocellulosic substrates at a concentration of $20 \mathrm{mg} / \mathrm{mL}$ : (i) wheat straw slurry (steam explosion pretreated), kindly provided by Abengoa (Sevilla, Spain); (ii) brewers spent grain, kindly provided by Heineken (Amsterdam, The Netherlands); (iii) crystalline cellulose (Merck, Darmstadt, Germany) and (iv) PASC. Substrates were pretreated with the LPMO variants (final concentration $1 \mathrm{mg} / \mathrm{mL}$ ) for $16 \mathrm{~h}$ in $100 \mathrm{mM}$ sodium acetate buffer $\mathrm{pH} 5$ with $1 \mathrm{mM}$ ascorbic acid. After incubation, each pretreated substrate was saccharified with Celluclast 1.5 L (Novozymes, Copenhagen, Denmark), a basal cocktail with low $\beta$ glucosidase activity, but rich in cellobiohydrolase and endoglucanase activities, adjusted to $1 \mathrm{U}$ of $\beta$-glucosidase activity. Reactions were carried out for $24 \mathrm{~h}$ at $40^{\circ} \mathrm{C}$ and $1200 \mathrm{rpm}$. Samples were taken at different intervals and the glucose released was quantified in the supernatants using the Glucose-TR commercial kit (Spinreact, Girona, Spain), according to the manufacturer's instructions. Controls were treated equivalently without the previous LPMO pretreatment. All assays were performed in triplicate, and significant differences were studied using Student's $t$-test, considering a $p$ value $<0.05$ as the limit for statistical differences.

\section{Conclusions}

In summary, a novel LPMO discovered in the genome of T. amestolkiae has been successfully expressed in P. pastoris and characterized. The wild-type enzyme (TamAA9A-WT), which has a "linker-like" region in the C-terminal area, was the most efficient in enhancing the saccharification yield of cellulosic and lignocellulosic substrates. The results obtained with the two enzyme variants constructed, TamAA9A-CD (only with the catalytic domain) and TamAA9A-CBM (with a fungal CBM after the "linker-like region"), suggest that the 
presence of the native linker favors the efficiency of the LPMO, while the incorporation of the CBM resulted in a negative effect, probably because it affects protein folding. In any case, it has been corroborated that the pretreatment of plant biomass with these enzymes helped to increase the efficiency of the process. Furthermore, it is important to note that the LPMOs tested in this work were not only able to improve the saccharification of model substrates, such as crystalline cellulose or PASC, but they were also active on natural lignocellulosic residues, such as brewers spent grain or pretreated wheat straw, which highlights the potential of these LPMOs in the framework of a circular bioeconomy context.

Supplementary Materials: The following are available online at https:/ /www.mdpi.com/article/10 $.3390 /$ ijms222413611/s1. DNA and aminoacid sequence and molecular models of TamAA9A from T. amestolkiae; expression and deglycosylation experiments; $\mathrm{pH}$ and thermal stability of the different variants.

Author Contributions: J.A.M.-L. drafted the manuscript and performed the experiments. I.A.-F. designed and performed the phylogenetic analysis and enzyme models. F.C. helped with the cloning, production, and purification of the enzymes. R.L. helped with the design of the first cloning strategy and colorimetric enzyme detection. F.J.P. and N.M. performed the HPAEC experiments. A.P., L.I.d.E. and M.J.M. coordinated the study and critically reviewed the manuscript. All authors have read and agreed to the published version of the manuscript.

Funding: This work has been funded by Projects RTI2018-093683-B-I00 and PID2019-105838RB-C31 from the Spanish Ministry of Science and Innovation (MCIU/AEI/FEDER, UE), S2018/EMT-4459 from the Comunidad de Madrid, Grant and EU-H2020 H2020-NMBP-TR-IND-2018-2020.

Institutional Review Board Statement: Not applicable.

Informed Consent Statement: Not applicable.

Data Availability Statement: T. amestolkiae whole genome shotgun sequencing project is available at https:/ / www.ncbi.nlm.nih.gov/nuccore/MIKG00000000 (accessed on 15 December 2021).

Acknowledgments: We acknowledge support towards the publication fee by the CSIC Open Access Publication Support Initiative through its Unit of Information Resources for Research (URICI).

Conflicts of Interest: The authors declare no conflict of interest.

\section{References}

1. Gray, K.A.; Zhao, L.; Emptage, M. Bioethanol. Curr. Opin. Chem. Biol. 2006, 10, 141-146. [CrossRef]

2. Martínez, Á.T.; Ruiz-Dueñas, F.J.; Martínez, M.J.; del Río, J.C.; Gutiérrez, A. Enzymatic delignification of plant cell wall: From nature to mill. Curr. Opin. Biotechnol. 2009, 20, 348-357. [CrossRef]

3. Henrissat, B. A classification of glycosyl hydrolases based on amino acid sequence similarities. Biochem. J. 1991, 280, 309-316. [CrossRef]

4. Lynd, L.R.; Weimer, P.J.; van Zyl, W.H.; Pretorius, I.S. Microbial cellulose utilization: Fundamentals and biotechnology. Microbiol. Mol. Biol. Rev. 2002, 66, 506-577. [CrossRef]

5. Van Dyk, J.S.; Pletschke, B.I. A review of lignocellulose bioconversion using enzymatic hydrolysis and synergistic cooperation between enzymes-Factors affecting enzymes, conversion and synergy. Biotechnol. Adv. 2012, 30, 1458-1480. [CrossRef]

6. Reese, E.T.; Siu, R.G.H.; Levinson, H.S. The biological degradation of soluble cellulose derivatives and its relationship to the mechanism of cellulose hydrolysis. J. Bacteriol. 1950, 59, 485-497. [CrossRef]

7. Martínez, A.T. How to break down crystalline cellulose. Science 2016, 352, 1050-1051. [CrossRef]

8. Vaaje-Kolstad, G.; Westereng, B.; Horn, S.J.; Liu, Z.; Zhai, H.; Sørlie, M.; Eijsink, V.G.H. An Oxidative Enzyme Boosting the Enzymatic Conversion of Recalcitrant Polysaccharides. Science 2010, 330, 219-222. [CrossRef]

9. Lombard, V.; Golaconda Ramulu, H.; Drula, E.; Coutinho, P.M.; Henrissat, B. The carbohydrate-active enzymes database (CAZy) in 2013. Nucleic Acids Res. 2014, 42, D490-D495. [CrossRef]

10. Aachmann, F.L.; Sørlie, M.; Skjåk-Bræk, G.; Eijsink, V.G.H.; Vaaje-Kolstad, G. NMR structure of a lytic polysaccharide monooxygenase provides insight into copper binding, protein dynamics, and substrate interactions. Proc. Natl. Acad. Sci. USA 2012, 109, 18779-18784. [CrossRef]

11. Bissaro, B.; Røhr, Å.K.; Müller, G.; Chylenski, P.; Skaugen, M.; Forsberg, Z.; Horn, S.J.; Vaaje-Kolstad, G.; Eijsink, V.G.H. Oxidative cleavage of polysaccharides by monocopper enzymes depends on $\mathrm{H}_{2} \mathrm{O}_{2}$. Nat. Chem. Biol. 2017, 13, 1123-1128. [CrossRef]

12. Rieder, L.; Petrović, D.; Väljamäe, P.; Eijsink, V.G.H.; Sørlie, M. Kinetic Characterization of a Putatively Chitin-Active LPMO Reveals a Preference for Soluble Substrates and Absence of Monooxygenase Activity. ACS Catal. 2021, 11, 11685-11695. [CrossRef] 
13. Westereng, B.; Loose, J.S.M.; Vaaje-Kolstad, G.; Aachmann, F.L.; Sørlie, M.; Eijsink, V.G.H. Analytical Tools for Characterizing Cellulose-Active Lytic Polysaccharide Monooxygenases (LPMOs). In Cellulases: Methods and Protocols; Lübeck, M., Ed.; Springer: New York, NY, USA, 2018; pp. 219-246. ISBN 978-1-4939-7877-9.

14. Frommhagen, M.; Westphal, A.H.; van Berkel, W.J.H.; Kabel, M.A. Distinct Substrate Specificities and Electron-Donating Systems of Fungal Lytic Polysaccharide Monooxygenases. Front. Microbiol. 2018, 9, 1080. [CrossRef]

15. Kracher, D.; Scheiblbrandner, S.; Felice, A.K.G.; Breslmayr, E.; Preims, M.; Ludwicka, K.; Haltrich, D.; Eijsink, V.G.H.; Ludwig, R. Extracellular electron transfer systems fuel cellulose oxidative degradation. Science 2016, 352, 1098-1101. [CrossRef]

16. Martínez, A.T.; Ruiz-Dueñas, F.J.; Camarero, S.; Serrano, A.; Linde, D.; Lund, H.; Vind, J.; Tovborg, M.; Herold-Majumdar, O.M.; Hofrichter, M.; et al. Oxidoreductases on their way to industrial biotransformations. Biotechnol. Adv. 2017, 35, 815-831. [CrossRef]

17. Crouch, L.I.; Labourel, A.; Walton, P.H.; Davies, G.J.; Gilbert, H.J. The Contribution of Non-catalytic Carbohydrate Binding Modules to the Activity of Lytic Polysaccharide Monooxygenases. J. Biol. Chem. 2016, 291, 7439-7449. [CrossRef]

18. Forsberg, Z.; Sørlie, M.; Petrović, D.; Courtade, G.; Aachmann, F.L.; Vaaje-Kolstad, G.; Bissaro, B.; Røhr, Å.K.; Eijsink, V.G.H. Polysaccharide degradation by lytic polysaccharide monooxygenases. Curr. Opin. Struct. Biol. 2019, 59, 54-64. [CrossRef]

19. Rani Singhania, R.; Dixit, P.; Kumar Patel, A.; Shekher Giri, B.; Kuo, C.-H.; Chen, C.-W.; Di Dong, C. Role and significance of lytic polysaccharide monooxygenases (LPMOs) in lignocellulose deconstruction. Bioresour. Technol. 2021, 335, 125261. [CrossRef]

20. Eijsink, V.G.H.; Petrovic, D.; Forsberg, Z.; Mekasha, S.; Røhr, Å.K.; Várnai, A.; Bissaro, B.; Vaaje-Kolstad, G. On the functional characterization of lytic polysaccharide monooxygenases (LPMOs). Biotechnol. Biofuels 2019, 12, 58. [CrossRef]

21. Wang, D.; Li, Y.; Zheng, Y.; Hsieh, Y.S.Y. Recent Advances in Screening Methods for the Functional Investigation of Lytic Polysaccharide Monooxygenases. Front. Chem. 2021, 9, 119. [CrossRef]

22. Breslmayr, E.; Hanžek, M.; Hanrahan, A.; Leitner, C.; Kittl, R.; Šantek, B.; Oostenbrink, C.; Ludwig, R. A fast and sensitive activity assay for lytic polysaccharide monooxygenase. Biotechnol. Biofuels 2018, 11, 79. [CrossRef]

23. Kittl, R.; Kracher, D.; Burgstaller, D.; Haltrich, D.; Ludwig, R. Production of four Neurospora crassa lytic polysaccharide monooxygenases in Pichia pastoris monitored by a fluorimetric assay. Biotechnol. Biofuels 2012, 5, 79. [CrossRef]

24. de Eugenio, L.I.; Méndez-Líter, J.A.; Nieto-Domínguez, M.; Alonso, L.; Gil-Muñoz, J.; Barriuso, J.; Prieto, A.; Martínez, M.J. Differential $\beta$-glucosidase expression as a function of carbon source availability in Talaromyces amestolkiae: A genomic and proteomic approach. Biotechnol. Biofuels 2017, 10, 161. [CrossRef] [PubMed]

25. Prieto, A.; de Eugenio, L.; Méndez-Líter, J.A.; Nieto-Domínguez, M.; Murgiondo, C.; Barriuso, J.; Bejarano-Muñoz, L.; Martínez, M.J. Fungal glycosyl hydrolases for sustainable plant biomass valorization: Talaromyces amestolkiae as a model fungus. Int. Microbiol. 2021, 24, 545-558. [CrossRef]

26. Méndez-Líter, J.A.; de Eugenio, L.I.; Nieto-Domínguez, M.; Prieto, A.; Martínez, M.J. Hemicellulases from Penicillium and Talaromyces for lignocellulosic biomass valorization: A review. Bioresour. Technol. 2021, 324, 124623. [CrossRef]

27. Vaishnav, N.; Singh, A.; Adsul, M.; Dixit, P.; Sandhu, S.K.; Mathur, A.; Puri, S.K.; Singhania, R.R. Penicillium: The next emerging champion for cellulase production. Bioresour. Technol. Rep. 2018, 2, 131-140. [CrossRef]

28. Méndez-Líter, J.A.; Gil-Muñoz, J.; Nieto-Domínguez, M.; Barriuso, J.; de Eugenio, L.I.; Martínez, M.J. A novel, highly efficient $\beta$-glucosidase with a cellulose-binding domain: Characterization and properties of native and recombinant proteins. Biotechnol. Biofuels 2017, 10, 256. [CrossRef]

29. Méndez-Líter, J.A.; de Eugenio, L.I.; Prieto, A.; Martínez, M.J. The $\beta$-glucosidase secreted by Talaromyces amestolkiae under carbon starvation: A versatile catalyst for biofuel production from plant and algal biomass. Biotechnol. Biofuels 2018, 11, 123. [CrossRef]

30. Méndez-Líter, J.A.; Nieto-Domínguez, M.; Fernández de Toro, B.; González Santana, A.; Prieto, A.; Asensio, J.L.; Cañada, F.J.; de Eugenio, L.I.; Martínez, M.J. A glucotolerant $\beta$-glucosidase from the fungus Talaromyces amestolkiae and its conversion into a glycosynthase for glycosylation of phenolic compounds. Microb. Cell Fact. 2020, 19, 127. [CrossRef]

31. Nieto-Domínguez, M.; Prieto, A.; Fernández de Toro, B.; Cañada, F.J.; Barriuso, J.; Armstrong, Z.; Withers, S.G.; de Eugenio, L.I.; Martínez, M.J. Enzymatic fine-tuning for 2-(6-hydroxynaphthyl) $\beta$-d-xylopyranoside synthesis catalyzed by the recombinant $\beta$-xylosidase BxTW1 from Talaromyces amestolkiae. Microb. Cell Fact. 2016, 15, 171. [CrossRef]

32. Nieto-Domínguez, M.; Fernández de Toro, B.; de Eugenio, L.I.; Santana, A.G.; Bejarano-Muñoz, L.; Armstrong, Z.; Méndez-Líter, J.A.; Asensio, J.L.; Prieto, A.; Withers, S.G.; et al. Thioglycoligase derived from fungal GH3 $\beta$-xylosidase is a multi-glycoligase with broad acceptor tolerance. Nat. Commun. 2020, 11, 4864. [CrossRef]

33. Boraston, A.B.; Bolam, D.N.; Gilbert, H.J.; Davies, G.J. Carbohydrate-binding modules: Fine-tuning polysaccharide recognition. Biochem. J. 2004, 382, 769-781. [CrossRef] [PubMed]

34. Kojima, Y.; Várnai, A.; Ishida, T.; Sunagawa, N.; Petrovic, D.M.; Igarashi, K.; Jellison, J.; Goodell, B.; Alfredsen, G.; Westereng, B.; et al. A Lytic Polysaccharide Monooxygenase with Broad Xyloglucan Specificity from the Brown-Rot Fungus Gloeophyllum trabeum and Its Action on Cellulose-Xyloglucan Complexes. Appl. Environ. Microbiol. 2016, 82, 6557-6572. [CrossRef] [PubMed]

35. Hansson, H.; Karkehabadi, S.; Mikkelsen, N.; Douglas, N.R.; Kim, S.; Lam, A.; Kaper, T.; Kelemen, B.; Meier, K.K.; Jones, S.M.; et al. High-resolution structure of a lytic polysaccharide monooxygenase from Hypocrea jecorina reveals a predicted linker as an integral part of the catalytic domain. J. Biol. Chem. 2017, 292, 19099-19109. [CrossRef] [PubMed]

36. Vaquero, M.E.; Barriuso, J.; Medrano, F.J.; Prieto, A.; Martínez, M.J. Heterologous expression of a fungal sterol esterase/lipase in different hosts: Effect on solubility, glycosylation and production. J. Biosci. Bioeng. 2015, 120, 637-643. [CrossRef] 
37. Petrović, D.M.; Bissaro, B.; Chylenski, P.; Skaugen, M.; Sørlie, M.; Jensen, M.S.; Aachmann, F.L.; Courtade, G.; Várnai, A.; Eijsink, V.G.H. Methylation of the N-terminal histidine protects a lytic polysaccharide monooxygenase from auto-oxidative inactivation. Protein Sci. 2018, 27, 1636-1650. [CrossRef] [PubMed]

38. Breslmayr, E.; Daly, S.; Požgajčić, A.; Chang, H.; Rezić, T.; Oostenbrink, C.; Ludwig, R. Improved spectrophotometric assay for lytic polysaccharide monooxygenase. Biotechnol. Biofuels 2019, 12, 283. [CrossRef]

39. Macauley-Patrick, S.; Fazenda, M.L.; McNeil, B.; Harvey, L.M. Heterologous protein production using the Pichia pastoris expression system. Yeast 2005, 22, 249-270. [CrossRef]

40. Liu, B.; Olson, Å.; Wu, M.; Broberg, A.; Sandgren, M. Biochemical studies of two lytic polysaccharide monooxygenases from the white-rot fungus Heterobasidion irregulare and their roles in lignocellulose degradation. PLoS ONE 2017, 12, e0189479. [CrossRef]

41. Maruyama, N.; Katsube, T.; Wada, Y.; Oh, M.H.; Barba De La Rosa, A.P.; Okuda, E.; Nakagawa, S.; Utsumi, S. The roles of the $\mathrm{N}$-linked glycans and extension regions of soybean beta-conglycinin in folding, assembly and structural features. Eur. J. Biochem. 1998, 258, 854-862. [CrossRef]

42. Frommhagen, M.; Westphal, A.H.; Hilgers, R.; Koetsier, M.J.; Hinz, S.W.A.; Visser, J.; Gruppen, H.; van Berkel, W.J.H.; Kabel, M.A. Quantification of the catalytic performance of C1-cellulose-specific lytic polysaccharide monooxygenases. Appl. Microbiol. Biotechnol. 2018, 102, 1281-1295. [CrossRef] [PubMed]

43. Singh, R.K.; Blossom, B.M.; Russo, D.A.; van Oort, B.; Croce, R.; Jensen, P.E.; Felby, C.; Bjerrum, M.J. Thermal unfolding and refolding of a lytic polysaccharide monooxygenase from Thermoascus aurantiacus. RSC Adv. 2019, 9, 29734-29742. [CrossRef]

44. Kadowaki, M.A.S.; Várnai, A.; Jameson, J.-K.; Leite, A.E.T.; Costa-Filho, A.J.; Kumagai, P.S.; Prade, R.A.; Polikarpov, I.; Eijsink, V.G.H. Functional characterization of a lytic polysaccharide monooxygenase from the thermophilic fungus Myceliophthora thermophila. PLoS ONE 2018, 13, e0202148. [CrossRef]

45. Agrawal, D.; Basotra, N.; Balan, V.; Tsang, A.; Chadha, B.S. Discovery and Expression of Thermostable LPMOs from Thermophilic Fungi for Producing Efficient Lignocellulolytic Enzyme Cocktails. Appl. Biochem. Biotechnol. 2020, 191, 463-481. [CrossRef]

46. Zhang, R.; Liu, Y.; Zhang, Y.; Feng, D.; Hou, S.; Guo, W.; Niu, K.; Jiang, Y.; Han, L.; Sindhu, L.; et al. Identification of a thermostable fungal lytic polysaccharide monooxygenase and evaluation of its effect on lignocellulosic degradation. Appl. Microbiol. Biotechnol. 2019, 103, 5739-5750. [CrossRef]

47. Tuveng, T.R.; Jensen, M.S.; Fredriksen, L.; Vaaje-Kolstad, G.; Eijsink, V.G.H.; Forsberg, Z. A thermostable bacterial lytic polysaccharide monooxygenase with high operational stability in a wide temperature range. Biotechnol. Biofuels 2020, 13, 194. [CrossRef] [PubMed]

48. Sun, Y.; Cheng, J. Hydrolysis of lignocellulosic materials for ethanol production: A review. Bioresour. Technol. 2002, 83, 1-11. [CrossRef]

49. Wang, Y.; Yuan, H.; Wang, J.; Yu, Z. Truncation of the cellulose binding domain improved thermal stability of endo-beta-1,4glucanase from Bacillus subtilis JA18. Bioresour. Technol. 2009, 100, 345-349. [CrossRef]

50. Forsberg, Z.; Mackenzie, A.K.; Sørlie, M.; Røhr, Å.K.; Helland, R.; Arvai, A.S.; Vaaje-Kolstad, G.; Eijsink, V.G.H. Structural and functional characterization of a conserved pair of bacterial cellulose-oxidizing lytic polysaccharide monooxygenases. Proc. Natl. Acad. Sci. USA 2014, 111, 8446-8451. [CrossRef] [PubMed]

51. Arfi, Y.; Shamshoum, M.; Rogachev, I.; Peleg, Y.; Bayer, E.A. Integration of bacterial lytic polysaccharide monooxygenases into designer cellulosomes promotes enhanced cellulose degradation. Proc. Natl. Acad. Sci. USA 2014, 111, 9109-9114. [CrossRef]

52. Borisova, A.S.; Isaksen, T.; Dimarogona, M.; Kognole, A.A.; Mathiesen, G.; Várnai, A.; Røhr, Å.K.; Payne, C.M.; Sørlie, M.; Sandgren, M.; et al. Structural and Functional Characterization of a Lytic Polysaccharide Monooxygenase with Broad Substrate Specificity. J. Biol. Chem. 2015, 290, 22955-22969. [CrossRef]

53. Chalak, A.; Villares, A.; Moreau, C.; Haon, M.; Grisel, S.; d'Orlando, A.; Herpoël-Gimbert, I.; Labourel, A.; Cathala, B.; Berrin, J.-G. Influence of the carbohydrate-binding module on the activity of a fungal AA9 lytic polysaccharide monooxygenase on cellulosic substrates. Biotechnol. Biofuels 2019, 12, 206. [CrossRef]

54. Vaaje-Kolstad, G.; Forsberg, Z.; Loose, J.S.M.; Bissaro, B.; Eijsink, V.G.H. Structural diversity of lytic polysaccharide monooxygenases. Curr. Opin. Struct. Biol. 2017, 44, 67-76. [CrossRef]

55. Danneels, B.; Tanghe, M.; Desmet, T. Structural Features on the Substrate-Binding Surface of Fungal Lytic Polysaccharide Monooxygenases Determine Their Oxidative Regioselectivity. Biotechnol. J. 2019, 14, e1800211. [CrossRef]

56. Olusola, O.; Anmoldeep, R.; Mayank, G.; Chandra, K.V.; Kumar, V.P.; Shams, Y.S.; Maia, K. Synergistic Action of a Lytic Polysaccharide Monooxygenase and a Cellobiohydrolase from Penicillium funiculosum in Cellulose Saccharification under High-Level Substrate Loading. Appl. Environ. Microbiol. 2021, 86, e01769-20.

57. Semenova, M.V.; Gusakov, A.V.; Telitsin, V.D.; Rozhkova, A.M.; Kondratyeva, E.G.; Sinitsyn, A.P. Purification and characterization of two forms of the homologously expressed lytic polysaccharide monooxygenase (PvLPMO9A) from Penicillium verruculosum. Biochim. Biophys. Acta Proteins Proteom. 2020, 1868, 140297. [CrossRef]

58. Müller, G.; Várnai, A.; Johansen, K.S.; Eijsink, V.G.H.; Horn, S.J. Harnessing the potential of LPMO-containing cellulase cocktails poses new demands on processing conditions. Biotechnol. Biofuels 2015, 8, 187. [CrossRef]

59. Jung, S.; Song, Y.; Kim, H.M.; Bae, H.-J. Enhanced lignocellulosic biomass hydrolysis by oxidative lytic polysaccharide monooxygenases (LPMOs) GH61 from Gloeophyllum trabeum. Enzym. Microb. Technol. 2015, 77, 38-45. [CrossRef] 
60. Chomczynski, P.; Sacchi, N. Single-step method of RNA isolation by acid guanidinium thiocyanate-phenol-chloroform extraction. Anal. Biochem. 1987, 162, 156-159. [CrossRef]

61. Katoh, K.; Kuma, K.; Toh, H.; Miyata, T. MAFFT version 5: Improvement in accuracy of multiple sequence alignment. Nucleic Acids Res. 2005, 33, 511-518. [CrossRef]

62. Guindon, S.; Gascuel, O. A Simple, Fast, and Accurate Algorithm to Estimate Large Phylogenies by Maximum Likelihood. Syst. Biol. 2003, 52, 696-704. [CrossRef] [PubMed]

63. Darriba, D.; Taboada, G.L.; Doallo, R.; Posada, D. ProtTest 3: Fast selection of best-fit models of protein evolution. Bioinformatics 2011, 27, 1164-1165. [CrossRef]

64. Robert, X.; Gouet, P. Deciphering key features in protein structures with the new ENDscript server. Nucleic Acids Res. 2014, 42, W320-W324. [CrossRef]

65. Waterhouse, A.; Bertoni, M.; Bienert, S.; Studer, G.; Tauriello, G.; Gumienny, R.; Heer, F.T.; de Beer, T.A.P.; Rempfer, C.; Bordoli, L.; et al. SWISS-MODEL: Homology modelling of protein structures and complexes. Nucleic Acids Res. 2018, 46, W296-W303. [CrossRef]

66. Jumper, J.; Evans, R.; Pritzel, A.; Green, T.; Figurnov, M.; Ronneberger, O.; Tunyasuvunakool, K.; Bates, R.; Žídek, A.; Potapenko, A.; et al. Highly accurate protein structure prediction with AlphaFold. Nature 2021, 596, 583-589. [CrossRef]

67. Baek, M.; DiMaio, F.; Anishchenko, I.; Dauparas, J.; Ovchinnikov, S.; Lee, G.R.; Wang, J.; Cong, Q.; Kinch, L.N.; Schaeffer, R.D.; et al. Accurate prediction of protein structures and interactions using a three-track neural network. Science 2021, 373, 871-876. [CrossRef]

68. Zhang, Y.-H.P.; Cui, J.; Lynd, L.R.; Kuang, L.R. A transition from cellulose swelling to cellulose dissolution by o-phosphoric acid: Evidence from enzymatic hydrolysis and supramolecular structure. Biomacromolecules 2006, 7, 644-648. [CrossRef] 